\title{
Conjugated action and methods for crowning in face-hobbed spiral bevel and hypoid gear drives through the Spirac system
}

\author{
Ignacio Gonzalez-Perez ${ }^{\mathrm{a}}$, Alfonso Fuentes-Aznar ${ }^{\mathrm{b}}$ \\ ${ }^{a}$ Polytechnic University of Cartagena, Department of Mechanical Engineering, Materials and Manufacturing, Cartagena, Murcia, SPAIN \\ ${ }^{b}$ Rochester Institute of Technology, Department of Mechanical Engineering, Rochester, NY, USA
}

\begin{abstract}
An analytical method for derivation of basic machine-tool settings that allows the conjugated action in face-hobbed spiral bevel and hypoid gear drives wherein the gear is not generated is proposed. This approach is used as starting point for investigation of further methods of crowning as the one where crowning is achieved through application of a tilt angle. A new approach where crowning is achieved through the application of modified roll between the rotations of the head-cutter and the pinion is proposed. It is based on the application of a two-term Fourier series of a parabolic function to provide a continuous and periodic function that is required in a continuous non-indexing process as face-hobbing. The existing and proposed approaches for crowning have been tested by the application of tooth contact analysis and geometry comparison. The results show that the proposed approach does not yield unloaded transmission errors and allows independent crowning at both tooth sides to get acceptable formations of the bearing contact for both rotational directions. Two numerical examples of design corresponding to a spiral bevel gear drive and a hypoid gear drive are presented as well starting from their basic data.
\end{abstract}

Keywords: spiral bevel and hypoid gears, face-hobbing, conjugated action, modified roll, tooth contact analysis

\section{Introduction}

Face-hobbing is widely applied in the manufacturing of spiral bevel and hypoid gears due to its high productivity. Among the face-hobbing processes, the Spirac system can be used as an exact or conjugated tooth system either in spiral bevel or hypoid gear drives [1]. In this system, the gear is not generated whereas the pinion is generated. The generation of the pinion is performed by a head-cutter where the gear acts as an imaginary tool. In these conditions, conjugated action between pinion and gear is feasible and line contact without unloaded transmission errors are possible.

Many efforts have been directed towards the determination of appropriate basic machine-tool settings in spiral bevel and hypoid gear drives that allow the bearing contact to be localized and to be less sensitive to alignment and manufacturing errors. These processes are usually accompanied by an increment of the level of transmission errors that the different methodologies try to keep under control. In [2,3] a higher order modification of the machine-tool settings is proposed to correct tooth flank form machining errors in face-hobbed spiral bevel and hypoid gears. Gear flank modifications are proposed in [4] based on a desired ease-off topography. Another ease-off based compensation is proposed in [5] to compensate imperfections of the machining process in hypoid gear drives providing corrections to the machine-tool settings of the pinion. Analytical determination of basic machine-tool settings of the gear has been performed in [6] for spiral bevel and hypoid gears, either in face-milling or face-hobbing. Then, application of local synthesis [7] allows the basic machine-tool settings of the pinion to be determined for a desired conditions of contact with the gear, although this process has been applied just for face-milled spiral bevel gear drives. An alternative and more general methodology to find these basic machine-tool settings in face-milled pinions (and extendable to facehobbed pinions) is proposed in [8] based on an optimization process that minimizes the distances between a target tooth surface and a manufactured tooth surface, where the definition of the target pinion tooth surface is based on given contact conditions with the gear tooth surface.

Few efforts have been directed towards the analytical determination of the basic machine-tool settings of the pinion that provide conjugated action with the gear in a spiral bevel or a hypoid gear drive. It can be due to the fact that such 
a contact condition is very sensitive to errors of alignment. However, analytical determination of the tool settings that provide conjugated action is very useful as a starting point for investigation of methods for crowning and localization of the bearing contact. That investigation requires a deep knowledge of the kinematics of the generating process and how each machine-tool setting affects the contact condition of the gear drive starting from the condition of conjugated action between the pinion and the gear. In [9] a computational generation model of face-hobbed spiral bevel gears was implemented considering the Cyclo-palloid system in which two coupled head cutters were considered, providing the machine-tool settings of pinion and gear to get conjugated action, and providing methods for localization of the bearing contact and compensation of errors of alignment.

Few publications have been found regarding the application of the Spirac system in computational models of gear tooth surface generation. A computational model for both non-generated and generated face-hobbed gears is presented in [10]. In [11] a general computational model for face-hobbed hypoid gears is presented including the Spirac system. Later, in [12] a conversion of machine-tool settings between a cradle-style hypoid generator and a six-axis control numerical machine is implemented, considering the Spirac system as a numerical example. Finally, an interesting approach to design the tooth surface topography considering the Spirac system is represented in [13].

Besides these recent publications, there are still some issues that require some attention. In the Spirac system, localization of the bearing contact (basically through the longitudinal crowning of the gear tooth surfaces) has been based traditionally on the application of a tilt angle [14]. The principal drawback of the Spirac system is that both sides of the gear tooth surfaces, the convex and the concave tooth surfaces, are generated simultaneously, and consequently, a good contact pattern in one side of the gear tooth surfaces not always involves an acceptable contact pattern in the other side. An alternative method for crowning of the pinion tooth surfaces in the Spirac system will be presented here based on the application of modified roll with the goal to get a good contact pattern in both sides of the teeth. On the other hand, application of modified roll is an issue that requires special attention in a face-hobbing process. Some modified roll functions are not periodic and consequently only valid for face-milling, but not for a continuous non-indexing process as face-hobbing is.

The main goals of the performed research can be summarized as follows:

(1) Analytical determination of the basic machine-tool settings that are able to get conjugated action in face-hobbed spiral bevel and hypoid gear drives considering the Spirac system. This conjugated action, that involves line contact and no unloaded transmission errors, acts as a starting point for the investigation of methods to crown the gear tooth surfaces and localize the bearing contact, including the traditional approach based on the application of a tilt angle and a proposed approach based on the application of modified roll.

(2) Compensation of errors of alignment through the redesign of the pinion tooth surfaces. Such a redesign has to be able to restore the contact conditions through the analytical determination of the basic machine-tool settings when such errors of alignment are present and known ahead. This approach may be applied to compensate errors of alignment due to shaft deflections for a given design load. Although the analytical determination of the basic machine-tool settings to compensate errors of alignment can work just for one direction of rotation (since the errors of alignment due to shaft deflections are different for the other direction of rotation), an approach to get an acceptable contact pattern in the other side of the teeth when the rotation is inverted is presented.

(3) Proposal of a new approach for longitudinal crowning of the pinion tooth surfaces. It is based on the application of a periodic function in the relation between the rotation of the pinion and the rotation of the head cutter, which is named here as a gear-to-blade roll function. Such a function will be based in the approximation of a parabolic function with a two-term Fourier's series, which is a periodic one. Profile crowning will be based on existing approaches, even through application of blades with parabolic profile (providing crowning along the whole profile) or through blades with a parabolic top-rem profile (providing bottom relief to pinion and gear tooth surfaces).

Several numerical examples are presented for verification of the sought-for goals in this paper. Gear tooth surface generation is based on the existence of the envelope to the family of generating surfaces that the blade profiles describe in their relative motion respect to the to-be-generated gear. Generation of the gear tooth surfaces by the head-cutter is based on application of coordinate transformation and the fulfillment of the corresponding equations of meshing, which can be refereed to many previous publications $[7,10,15]$. Tooth contact analysis is being applied as a tool of 
verification of the to-be-obtained contact patterns and functions of unloaded transmission errors. It considers three pairs of contacting teeth over two cycles of meshing. Therefore, the results show any possible issue in the process of load transfer between consecutive pairs of contacting teeth. This approach has been applied before in [16] and considers the tooth surfaces as rigid ones. Gear tooth surface comparison is being applied as an additional tool to check the amount of crowning that the different investigated approaches provide and to verify its validity, specially when both contacting sides of the gear teeth can be affected by the settings of the chosen approach for crowning.

\section{Analytical determination of basic machine-tool settings to get conjugated action}

The conditions for exact generation or conjugated action in a spiral bevel or a hypoid gear drive are well described in [1]. Basically, it is necessary that the tool of the gear and the tool of the pinion are located in such positions that the blade profiles of both tools are congruent and the axes of rotation of the head-cutters are aligned. In the exact formate method where the gear is not generated, it is required that the axis of the cradle for generation of the pinion coincides with the axis of the gear, acting the gear as an imaginary tool (actually, the motions of gear and pinion cradle are exactly the same). The advantage of this exact formate method is that can be easily applied either in spiral bevel gear drives or in hypoid gear drives.

\subsection{Conjugated action in a spiral bevel gear drive}

Figure 1 illustrates the location of the pinion head-cutter in a spiral bevel gear drive where the pinion and the gear are shown as well. Here, the blades of the pinion head-cutter are pointing towards the pinion root cone. The location of the gear head-cutter is not illustrated for the purpose of simplicity, but it can be imagined in the same location as the pinion head-cutter is, with its blades pointing towards the gear root cone and its axis of rotation coinciding with the pinion head-cutter one.

Several coordinate systems are considered in Figure 1. Systems $S_{m 1}$ and $S_{m 2}$ are rigidly connected to the frame of the machine for pinion and gear generation, respectively. Origin $O_{m 2}$ coincides with pinion and gear pitch apexes $O_{1}$ and $O_{2}$. Axis $x_{m 2}$ coincides with one of the gear pitch cone generatrices, forming the gear pitch cone angle $\gamma_{2}$ with the gear axis. It can be observed as well that axis $z_{m 1}$ is aligned with the gear axis. This condition is required for exact generation since the rotation of the pinion cradle about axis $z_{m 1}$ in pinion generation has to coincide with the rotation of the gear.

Center $O_{c}$ represents the center of rotation of pinion and gear head-cutters. Its position is given in the plane defined by coordinate axes $x_{m 2}$ and $y_{m 2}$, and is determined through the radial distance $S_{r 2}$ and cradle angle $q_{2}$ used for generation of the gear [17]

$$
\begin{aligned}
S_{r 2} & =\sqrt{A_{m}^{2}+r_{c}^{2}-2 A_{m} r_{c} \sin \left(\psi_{m}-v\right)} \\
q_{2} & =\arcsin \left[\frac{r_{c}}{S_{r 2}} \cos \left(\psi_{m}-v\right)\right]
\end{aligned}
$$

Here, $A_{m}=\overline{O_{m 2} P}$ is the gear mean cone distance, $r_{c}=\overline{O_{c} P}$ is the cutter radius, $\psi_{m}$ is the mean spiral angle of the gear, and $v$ is the slope angle used in the assembly of the blades to the head cutter (see [17]).

Point $F$ is obtained from the perpendicular to axis $x_{m 2}$ that passes through point $O_{c}$. Then axis $x_{m 1}$ is forced to pass through point $F$ and be perpendicular to axis $z_{m 1}$. The location of the same center $O_{c}$ in coordinate system $S_{m 1}$, which is required for pinion generation, is not straightforward. It is determined through the radial distance $S_{r 1}$ and cradle angle $q_{1}$ required in the generation of the pinion.

$$
\begin{aligned}
S_{r 1} & =S_{r 2} \sqrt{\sin ^{2} q_{2}+\cos ^{2} q_{2} \sin ^{2}\left(\gamma-\gamma_{1}\right)} \\
q_{1} & =\arctan \left[\frac{\tan q_{2}}{\sin \left(\gamma-\gamma_{1}\right)}\right]
\end{aligned}
$$

Here, $\gamma$ is the shaft angle of the gear drive and $\gamma_{1}$ is the pinion pitch angle. The sliding base $\Delta X_{B 1}$ machine-tool setting is required to locate the pinion pitch apex $O_{1}$ at point $O_{m 2}$

$$
\Delta X_{B 1}=S_{r 2} \cos q_{2} \cos \left(\gamma-\gamma_{1}\right)
$$




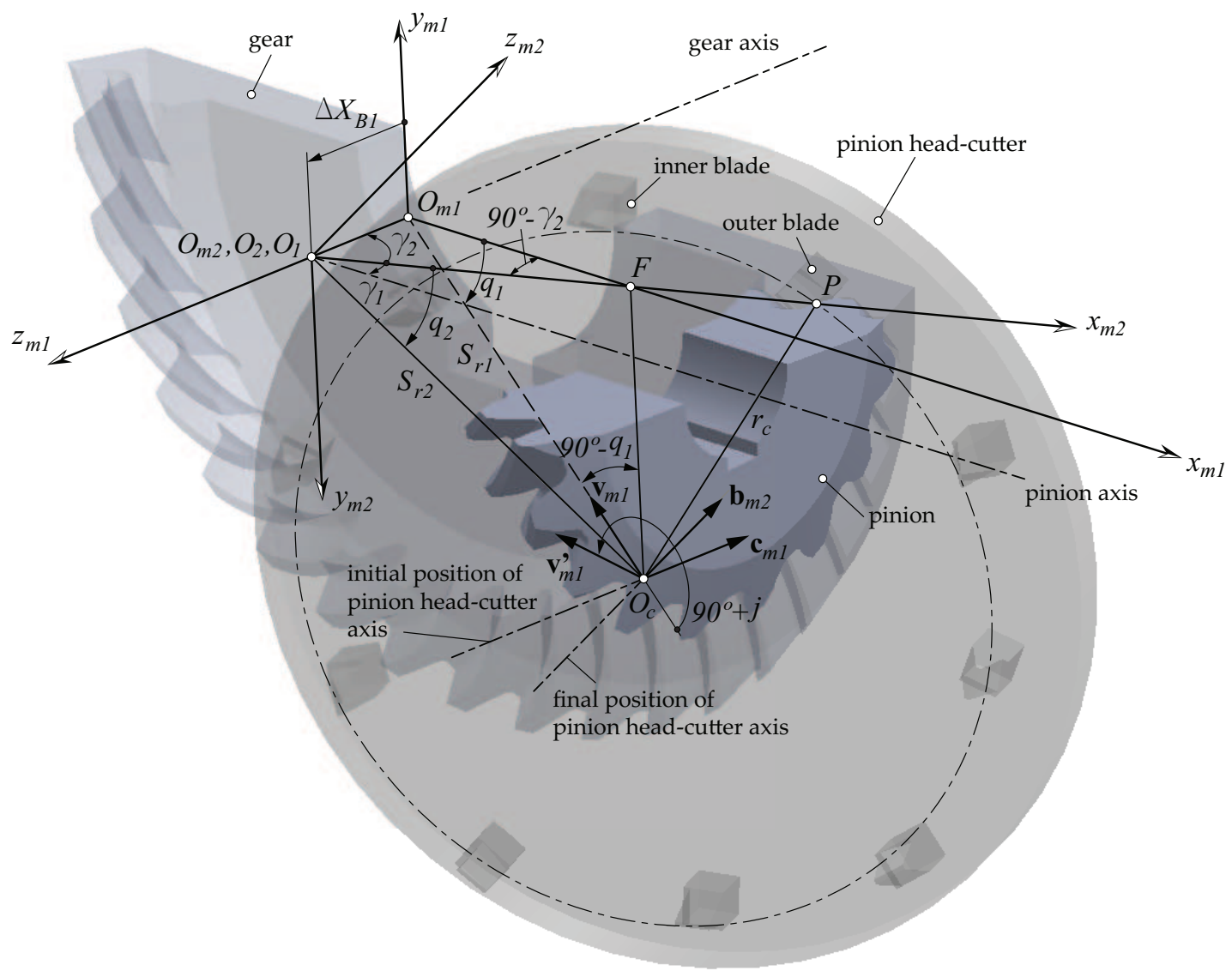

Figure 1: For illustration of machine-tool settings for pinion and gear generation in a spiral bevel gear drive with conjugated action. 
The axes of rotation of the head-cutters for both the pinion and the gear have to coincide with each other. Initially, the axis of the pinion head-cutter is perpendicular to the plane $\left(x_{m 1}, y_{m 1}\right)$ and its direction is given by unit vector $\mathbf{c}_{m 1}$, which is parallel to axis $z_{m 1}$ (see Figure 1). The axis of the gear head-cutter is perpendicular to the plane $\left(x_{m 2}, y_{m 2}\right)$ and its direction is given by unit vector $\mathbf{b}_{m 2}$, which is parallel to axis $z_{m 2}$. Since the axis of the pinion head-cutter has to coincide with the axis of the gear head-cutter, a swivel angle $j$ and a tilt angle $i$ are required for the assembly of the pinion head-cutter in coordinate system $S_{m 1}$ in order to align vector $\mathbf{c}_{m 1}$ with vector $\mathbf{b}_{m 2}$. The derivation of those angles is not straightforward. For that purpose, the following procedure is considered:

- A unit vector, in the direction of the gear head-cutter axis, is defined in system $S_{m 2}$ as

$$
\mathbf{b}_{m 2}=\left[\begin{array}{lll}
0 & 0 & 1
\end{array}\right]^{\mathrm{T}}
$$

- A unit vector, in the direction of the pinion head-cutter axis and before rotations $j$ and $i$ occur, is defined in system $S_{m 1}$ as

$$
\mathbf{c}_{m 1}=\left[\begin{array}{lll}
0 & 0 & -1
\end{array}\right]^{\mathrm{T}}
$$

This direction of the pinion head-cutter axis is pointed out in Figure 1 as initial position of pinion head-cutter axis.

- Vector $\mathbf{v}_{m 1}^{\prime}$ can be obtained by rotating vector $\mathbf{v}_{m 1}=\left[\begin{array}{lll}-\cos q_{1} & \sin q_{1} & 0\end{array}\right]^{\mathrm{T}}$ a swivel angle $j$ about vector $\mathbf{c}_{m 1}$ in clockwise direction

$$
\mathbf{v}_{m 1}^{\prime}=\left[\begin{array}{lll}
-\cos \left(q_{1}-j\right) & \sin \left(q_{1}-j\right) & 0
\end{array}\right]^{\mathrm{T}}
$$

- A new vector $\mathbf{c}^{\prime}{ }_{m 1}$ is obtained by rotating vector $\mathbf{c}_{m 1}$ a tilt angle $i$ about vector $\mathbf{v}^{\prime}{ }_{m 1}$ in counterclockwise direction

$$
\begin{gathered}
\mathbf{c}^{\prime}{ }_{m 1}=\left[\begin{array}{ccc}
\cos i\left[1-\cos ^{2}\left(q_{1}-j\right)\right]+\cos ^{2}\left(q_{1}-j\right) & -(1-\cos i) \sin \left(q_{1}-j\right) \cos \left(q_{1}-j\right) & \sin i \sin \left(q_{1}-j\right) \\
-(1-\cos i) \sin \left(q_{1}-j\right) \cos \left(q_{1}-j\right) & \cos i\left[1-\sin ^{2}\left(q_{1}-j\right)\right]+\sin ^{2}\left(q_{1}-j\right) & \sin i \cos \left(q_{1}-j\right) \\
-\sin i \sin \left(q_{1}-j\right) & -\sin i \cos \left(q_{1}-j\right) & \cos i
\end{array}\right] \cdot\left[\begin{array}{c}
0 \\
0 \\
-1
\end{array}\right] \\
\mathbf{c}^{\prime}{ }_{m 1}=\left[\begin{array}{c}
-\sin i \sin \left(q_{1}-j\right) \\
-\sin i \cos \left(q_{1}-j\right) \\
-\cos i
\end{array}\right]
\end{gathered}
$$

- On the other hand, vector $\mathbf{b}_{m 2}$ can be expressed in system $S_{m 1}$ (and denoted as $\mathbf{b}_{m 1}$ ) after coordinate transformation from system $S_{m 2}$ to system $S_{m 1}$

$$
\begin{gathered}
\mathbf{b}_{m 1}=\mathbf{L}_{m 1 m 2} \mathbf{b}_{m 2} \\
\mathbf{b}_{m 1}=\left[\begin{array}{ccc}
\sin \gamma_{2} & 0 & -\cos \gamma_{2} \\
0 & -1 & 0 \\
-\cos \gamma_{2} & 0 & -\sin \gamma_{2}
\end{array}\right] \cdot\left[\begin{array}{l}
0 \\
0 \\
1
\end{array}\right]=\left[\begin{array}{c}
-\cos \gamma_{2} \\
0 \\
-\sin \gamma_{2}
\end{array}\right]
\end{gathered}
$$

- Since vector $\mathbf{c}^{\prime}{ }_{m 1}$ has to match vector $\mathbf{b}_{m 1}$, the following equations are obtained

$$
\begin{aligned}
-\sin i \sin \left(q_{1}-j\right) & =-\cos \gamma_{2} \\
-\sin i \cos \left(q_{1}-j\right) & =0 \\
-\cos i & =-\sin \gamma_{2}
\end{aligned}
$$

Here, $\gamma_{2}$ is the gear pitch angle that can be expressed as $\gamma_{2}=\gamma-\gamma_{1}$.

- The solution of the previous equations provides the following relations for the tilt angle $i$ and the swivel angle $j$

$$
\begin{aligned}
i & =\frac{\pi}{2}-\left(\gamma-\gamma_{1}\right) \\
j & =q_{1}-\frac{\pi}{2}
\end{aligned}
$$


and allows the pinion head-cutter axis to reach what is pointed out in Figure 1 as final position of the pinion head-cutter axis.

Regarding the machine root angles $\gamma_{R 2}$ and $\gamma_{R 1}$ that provide the orientation of gear and pinion axes respect to axes $x_{m 2}$ and $x_{m 1}$, respectively, are given as

$$
\begin{aligned}
& \gamma_{R 2}=\gamma_{2} \\
& \gamma_{R 1}=\gamma-90^{\circ}
\end{aligned}
$$

Regarding the gear-to-blade roll ratios, $m_{g b, 2}$ and $m_{g b, 1}$, of gear and pinion, respectively, and the gear-to-cradle roll ratio $m_{g c, 1}$ of the pinion, are given as

$$
\begin{aligned}
& m_{g b, 2}=\frac{N_{b}}{N_{2}} \\
& m_{g b, 1}=\frac{N_{b}}{N_{1}} \\
& m_{g c, 1}=\frac{N_{2}}{N_{1}}
\end{aligned}
$$

where $N_{b}$ is the number of blade pairs, $N_{1}$ is the pinion tooth number, and $N_{2}$ is the gear tooth number.

\subsection{Conjugated action in a hypoid gear drive}

Figure 2 shows the assembly of the pinion head-cutter in a hypoid gear drive where pinion and gear are illustrated as well. The same conditions as in a spiral bevel gear drive are required here for exact generation. A similar procedure as presented in the previous subsection is followed here to set up coordinate systems $S_{m 1}$ and $S_{m 2}$ and locate center $O_{c}$. Crossing points $O_{c 1}$ and $O_{c 2}$ on the shortest center distance between pinion and gear axes are illustrated as well.

Unlike the spiral bevel gear drive, here axis $x_{m 2}$ does not coincide with the gear pitch cone generatrix (see details in Figure 3). This is because the reference height of the gear head-cutter $h_{r}$ does not coincide with the gear dedendum $b_{2}$ (this circumstance seeks a longer addendum in the pinion than in the gear as it is suggested in [17]). Therefore, origin $O_{m 2}$ is not located at the gear axis and a sliding base $\Delta X_{B 2}=-\left(b_{2}-h_{r}\right)$ is required to locate point $O_{2}$ on the gear axis. Here, the reference height $h_{r}$ is taken as

$$
h_{r}=1.25 \frac{\left(a_{2}+b_{2}\right)}{2.25}
$$

where $a_{2}$ is the gear addendum.

Center $O_{c}$ (see Figure 2) of pinion and gear head-cutters is given in the plane $\left(x_{m 2}, y_{m 2}\right)$ and is determined through the same machine-tool settings $S_{r_{2}}$ and $q_{2}$ that those expressed in (1) and (2) for the generation of the gear.

By combining illustrations in Figure 2 and Figure 3, the radial distance $S_{r 1}$ and the cradle angle $q_{1}$ for the pinion can be obtained as

$$
\begin{aligned}
S_{r 1} & =\sqrt{\left(S_{r 2} \sin q_{2}\right)^{2}+\left(S_{r 2} \cos q_{2} \sin \gamma_{2}+\Delta X_{B 2} \cos \gamma_{2}\right)^{2}} \\
q_{1} & =\arctan \left[\frac{S_{r 2} \sin q_{2}}{S_{r 2} \cos q_{2} \sin \gamma_{2}+\Delta X_{B 2} \cos \gamma_{2}}\right]
\end{aligned}
$$

Here, $\gamma_{2}$ is the gear pitch angle.

The location of the pinion pitch apex $O_{1}$ (see Figure 2) requires a sliding base $\Delta X_{B 1}$, a machine offset $\Delta X_{E 1}$ and a machine center to back $\Delta X_{D 1}$ as follows

$$
\begin{aligned}
\Delta X_{B 1} & =S_{r 2} \cos q_{2} \cos \gamma_{2}-\Delta X_{B 2} \sin \gamma_{2}-p_{2} \\
\Delta X_{E 1} & =e \\
\Delta X_{D 1} & =-p_{1}
\end{aligned}
$$




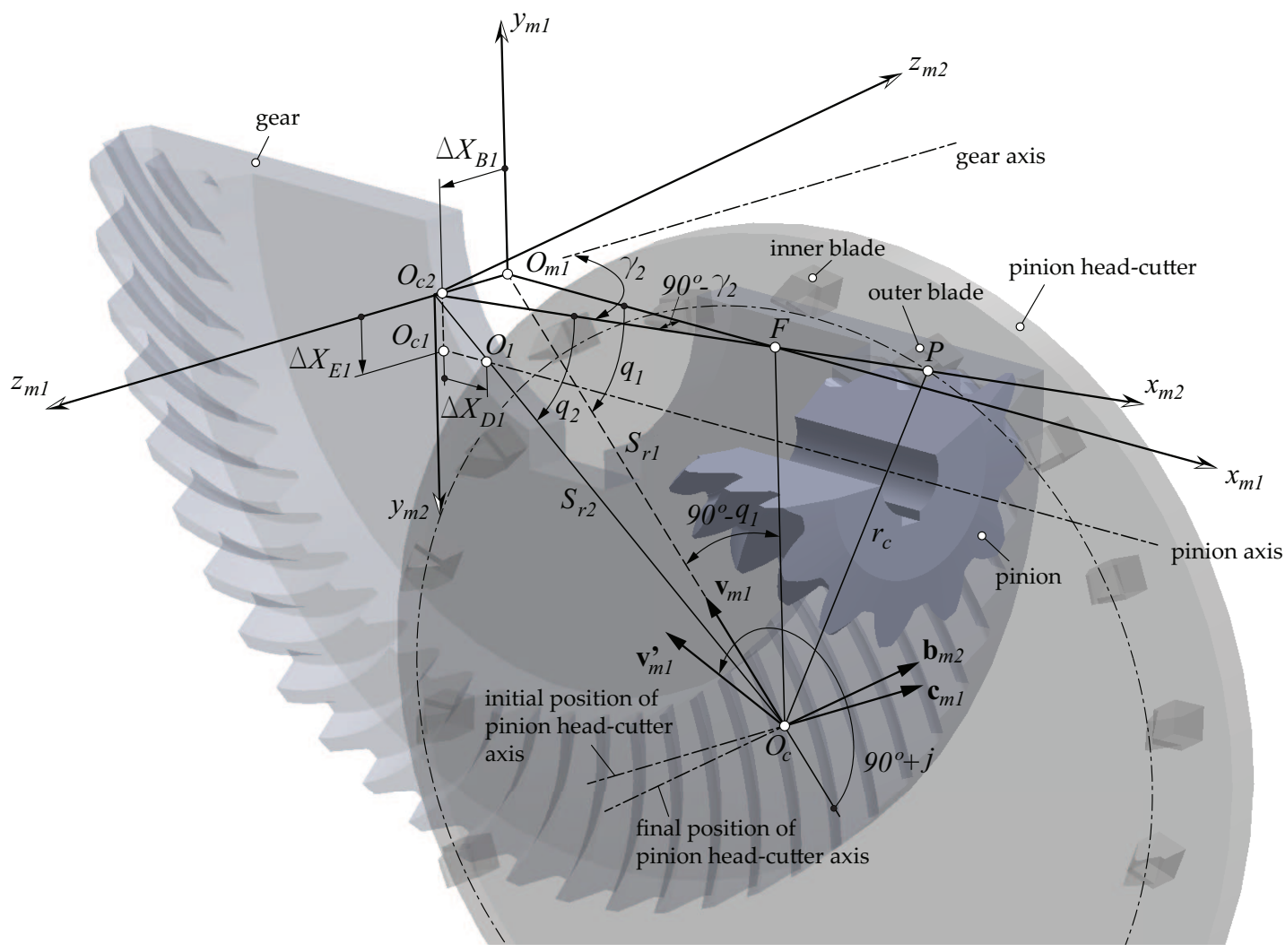

Figure 2: For illustration of machine-tool settings for pinion and gear generation in a hypoid gear drive with conjugated action.

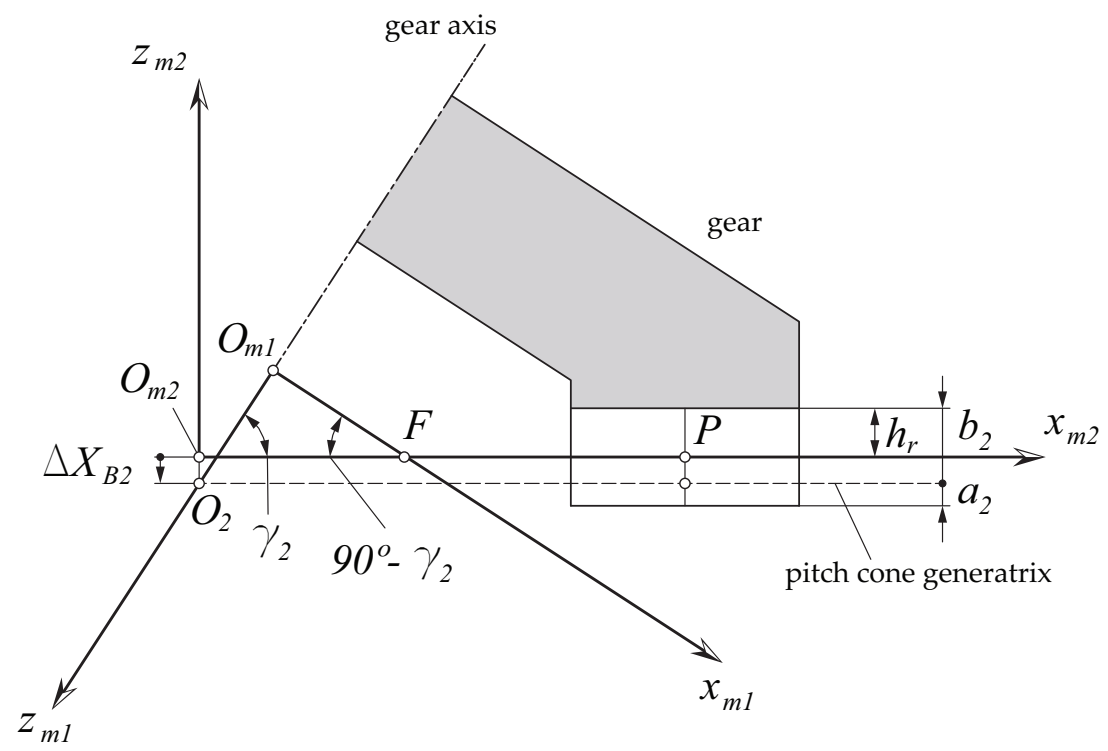

Figure 3: Detailed view of planes $\left(x_{m 2}, z_{m 2}\right)$ and $\left(x_{m 1}, z_{m 1}\right)$ for illustration of magnitudes $h_{r}, a_{2}, b_{2}$ and $\Delta X_{B 2}$ in the hypoid gear. 
Here, $p_{2}$ is the gear pitch apex beyond crossing point, $e$ is the gear set offset, and $p_{1}$ is the pinion pitch apex beyond crossing point. We recall that in a hypoid gear drive, machine centers to crossing points $\Delta X_{C 1}$ and $\Delta X_{C 2}$ are given instead of machine centers to back $\Delta X_{D 1}$ and $\Delta X_{D 2}$, yielding

$$
\begin{aligned}
& \Delta X_{C 2}=\Delta X_{D 2}+p_{2}=p_{2} \\
& \Delta X_{C 1}=\Delta X_{D 1}+p_{1}=0
\end{aligned}
$$

A similar procedure is required here for determination of the swivel angle $j$ and the tilt angle $i$ of the pinion headcutter, providing the following results (here, the use of variable $\gamma_{2}$ is mandatory since $\gamma_{2} \neq \gamma-\gamma_{1}$ in a hypoid gear drive)

$$
\begin{aligned}
& i=\frac{\pi}{2}-\gamma_{2} \\
& j=q_{1}-\frac{\pi}{2}
\end{aligned}
$$

The same relations of machine root angles and gear-to-blade and gear-to-cradle roll ratios are obtained as in the case of a spiral bevel gear drive.

\section{Compensation of errors of alignment through the redesign of the pinion tooth surfaces}

The basic idea for compensation of errors of alignment in the design of the gear drive is to take into account the relative position of the gear respect to the pinion in the positioning of the pinion head-cutter during the manufacturing of the pinion. Such errors of alignment can be due to shaft deflections when a given design load is transmitted. The procedure to compensate them is valid for one direction of rotation, since the to-be-derived machine-tool settings are the same for both sides of the pinion teeth and errors of alignment change when load varies or rotation is inverted. However, a procedure will be explained below to get an acceptable contact pattern for the other direction of rotation and the same design load. These errors can be defined as the pinion axial error $\Delta A_{1}$, the gear axial error $\Delta A_{2}$, the shaft angle error $\Delta \gamma$, and the shortest center distance error $\Delta E$ (an illustration of these errors can be found in [9] for a spiral bevel gear drive). The key point consists on considering the errors of alignment in the relative positioning of coordinate systems $S_{m 1}$ and $S_{m 2}$ represented in Figures 1 and 2. Figure 4 shows this new relative positioning of systems $S_{m 1}$ and $S_{m 2}$ considering the errors of alignment for a spiral bevel gear drive.

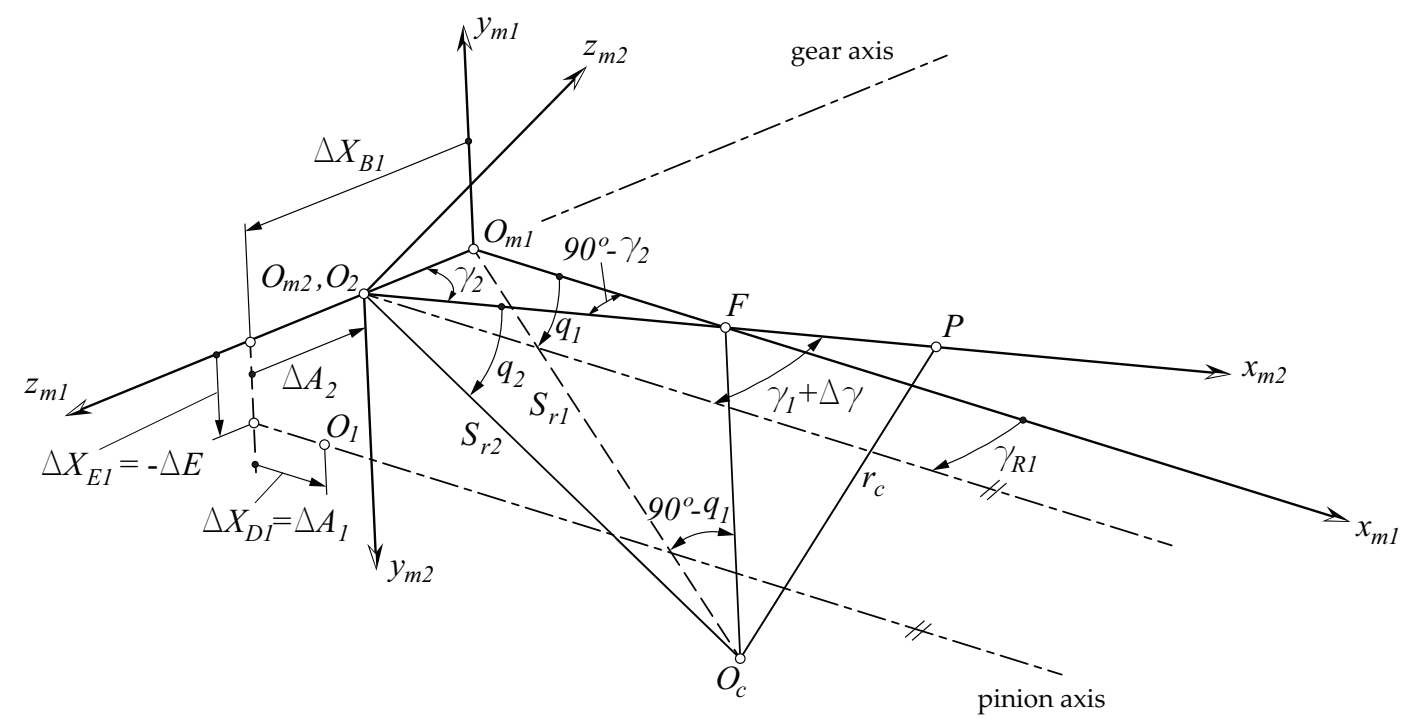

Figure 4: Illustration of machine-tool settings in a spiral bevel gear drive to compensate alignment errors. 
In the case of a spiral bevel gear drive, the machine-tool settings that are affected by errors of alignment are:

$$
\begin{aligned}
\Delta X_{B 1} & =S_{r 2} \cos q_{2} \cos \gamma_{2}+\Delta A_{2} \\
\Delta X_{E 1} & =-\Delta E \\
\Delta X_{D 1} & =\Delta A_{1} \\
\gamma_{R 1} & =\gamma-90^{\circ}+\Delta \gamma
\end{aligned}
$$

In the case of a hypoid gear drive, the procedure to compensate the alignment errors is similar. The machine-tool settings that are affected are:

$$
\begin{aligned}
\Delta X_{B 1} & =S_{r 2} \cos q_{2} \cos \gamma_{2}-\Delta X_{B 2} \sin \gamma_{2}-p_{2}+\Delta A_{2} \\
\Delta X_{E 1} & =e-\Delta E \\
\Delta X_{D 1} & =-p_{1}+\Delta A_{1} \\
\Delta X_{C 1} & =\Delta A_{1} \\
\gamma_{R 1} & =\gamma-90^{\circ}+\Delta \gamma
\end{aligned}
$$

\section{Longitudinal crowning of the pinion tooth surfaces through application of a tilt angle}

The usual procedure to crown the pinion tooth surfaces in the Spirac system is through application of a tilt angle [14]. Figure 5 shows how coordinate systems $S_{m 1}$ and $S_{m 2}$ are disposed when a reference tilt angle $\Delta i_{\text {ref }}$ and a modified mean spiral angle $\psi_{m}^{\prime}$ are applied for pinion generation in a spiral bevel gear drive (the procedure would be similar in the case of a hypoid gear drive and the differences are outlined at the end of this section).

The gear machine-tool settings are obtained as described in Section 2. The use of the term reference means that the head-cutter of the gear is tilted virtually (but not really) by angle $\Delta i_{r e f}$. This works as a mean to determine the pinion machine-tool settings that allows for matching the positioning of the pinion head-cutter with the virtual position of the gear head-cutter.

The modified mean spiral angle $\psi_{m}^{\prime}$ is given as $\psi_{m}^{\prime}=\psi_{m}+\Delta \psi_{m, \text { ref }}$ where $\Delta \psi_{m, r e f}$ is an additional reference spiral angle that is useful to control the crowning apex location of the pinion tooth surfaces.

The position of the pinion head-cutter respect to system $S_{m 1}$ requires determination of the swivel angle $j$ and the tilt angle $i$ as it was done in Section 2. This procedure is summarized as follows:

- A counterclockwise rotation $\Delta i_{r e f}$ of vector $\mathbf{b}_{m 2}$ about vector $\mathbf{a}_{m 2}=\left[\begin{array}{lll}-\cos \psi_{m}^{\prime} & -\sin \psi_{m}^{\prime} & 0\end{array}\right]^{T}$ is required. Here, vector $\mathbf{b}_{m 2}$ is parallel to axis $z_{m 2}$ and perpendicular to the gear root cone whereas vector $\mathbf{a}_{m 2}$ is perpendicular to the plane of tilting (see Figure 5). The resulting vector $\mathbf{b}_{m 2}^{\prime}$ is obtained as

$$
\begin{gathered}
\mathbf{b}_{m 2}^{\prime}=\left[\begin{array}{ccc}
\cos \Delta i_{r e f}\left[1-\cos ^{2} \psi_{m}^{\prime}\right]+\cos ^{2} \psi_{m}^{\prime} & \left(1-\cos \Delta i_{r e f}\right) \sin \psi_{m}^{\prime} \cos \psi_{m}^{\prime} & -\sin \Delta i_{r e f} \sin \psi_{m}^{\prime} \\
\left(1-\cos \Delta i_{r e f}\right) \sin \psi_{m}^{\prime} \cos \psi_{m}^{\prime} & \cos \Delta i_{r e f}\left(1-\sin ^{2} \psi_{m}^{\prime}\right)+\sin ^{2} \psi_{m}^{\prime} & \sin \Delta i_{r e f} \cos \psi_{m}^{\prime} \\
\sin \Delta i_{r e f} \sin \psi_{m}^{\prime} & -\sin \Delta i_{r e f} \cos \psi_{m}^{\prime} & \cos \Delta i_{r e f}
\end{array}\right] \cdot\left[\begin{array}{l}
0 \\
0 \\
1
\end{array}\right] \\
\mathbf{b}_{m 2}^{\prime}=\left[\begin{array}{c}
-\sin \Delta i_{r e f} \sin \psi_{m}^{\prime} \\
\sin \Delta i_{r e f} \cos \psi_{m}^{\prime} \\
\cos \Delta i_{r e f}
\end{array}\right]
\end{gathered}
$$

- Coordinate transformation from system $S_{m 2}$ to system $S_{m 1}$ provides vector $\mathbf{b}^{\prime}{ }_{m 1}$ as

$$
\begin{gathered}
\mathbf{b}_{m 1}^{\prime}=\mathbf{L}_{m 1 m 2} \mathbf{b}_{m 2}^{\prime} \\
\mathbf{b}_{m 1}^{\prime}=\left[\begin{array}{ccc}
\sin \gamma_{2} & 0 & -\cos \gamma_{2} \\
0 & -1 & 0 \\
-\cos \gamma_{2} & 0 & -\sin \gamma_{2}
\end{array}\right] \cdot\left[\begin{array}{c}
-\sin \Delta i_{r e f} \sin \psi_{m}^{\prime} \\
\sin \Delta i_{r e f} \cos \psi_{m}^{\prime} \\
\cos \Delta i_{r e f}
\end{array}\right]=\left[\begin{array}{c}
-\sin \Delta i_{r e f} \sin \psi_{m}^{\prime} \sin \gamma_{2}-\cos \Delta i_{r e f} \cos \gamma_{2} \\
-\sin \Delta i_{r e f} \cos \psi_{m}^{\prime} \\
\sin \Delta i_{r e f} \sin \psi_{m}^{\prime} \cos \gamma_{2}-\cos \Delta i_{r e f} \sin \gamma_{2}
\end{array}\right]
\end{gathered}
$$

- Vector $\mathbf{c}_{m 1}$ (see Section 2) becomes vector $\mathbf{c}^{\prime}{ }_{m 1}$ after rotations $j$ and $i$ are performed (see relation (2.1)). 


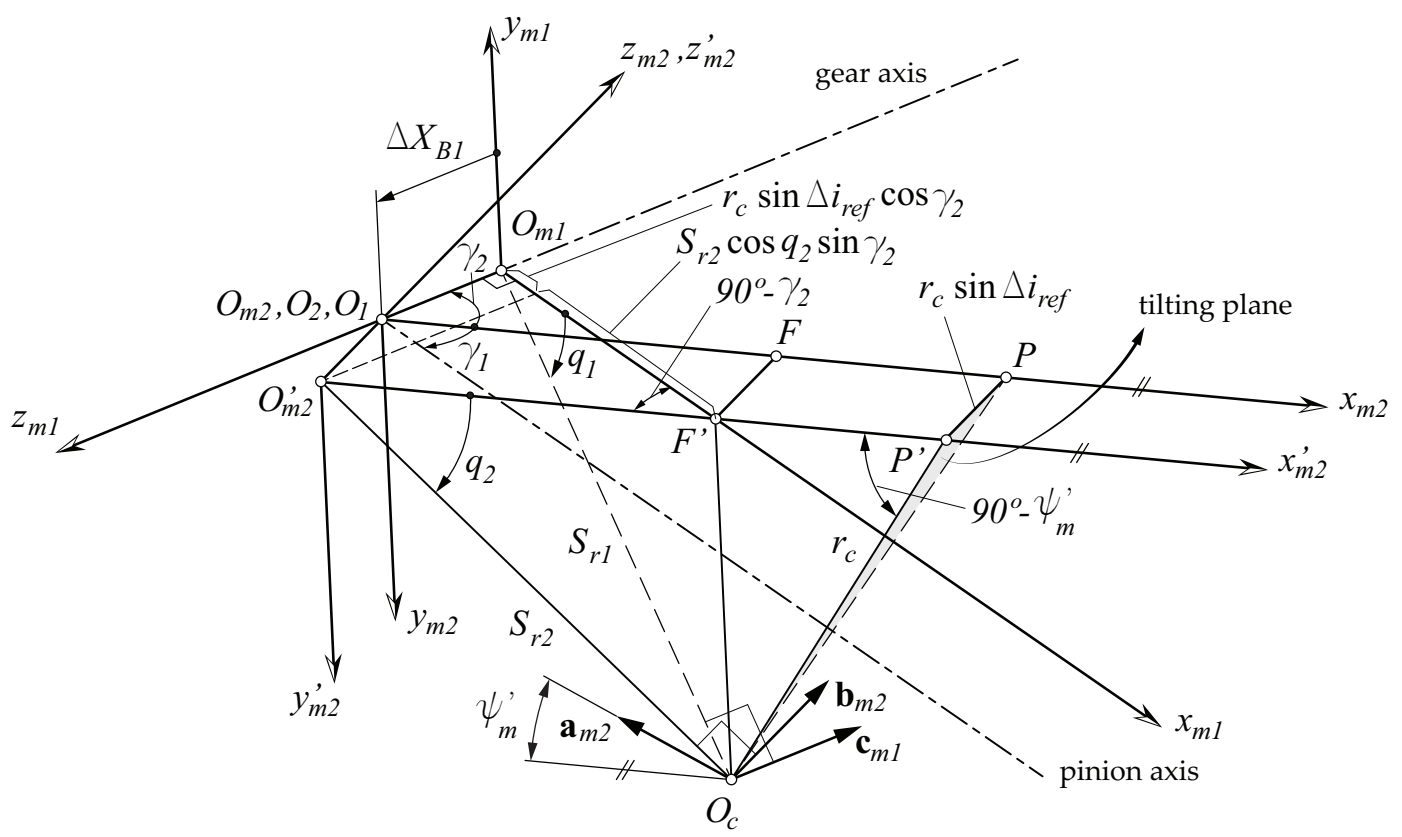

Figure 5: Illustration of machine-tool settings in a spiral bevel gear drive when a reference tilt angle $\Delta i_{r e f}$ and a modified mean spiral angle $\psi_{m}^{\prime}$ are applied.

- Since vector $\mathbf{c}^{\prime}{ }_{m 1}$ has to match vector $\mathbf{b}^{\prime}{ }_{m 1}$, the following equations are obtained

$$
\begin{aligned}
-\sin i \sin \left(q_{1}-j\right) & =-\sin \Delta i_{r e f} \sin \psi_{m}^{\prime} \sin \gamma_{2}-\cos \Delta i_{r e f} \cos \gamma_{2} \\
-\sin i \cos \left(q_{1}-j\right) & =-\sin \Delta i_{r e f} \cos \psi_{m}^{\prime} \\
-\cos i & =\sin \Delta i_{r e f} \sin \psi_{m}^{\prime} \cos \gamma_{2}-\cos \Delta i_{r e f} \sin \gamma_{2}
\end{aligned}
$$

- Solution of the previous equations provide the following relations for the tilt angle $i$ and the swivel angle $j$

$$
\begin{aligned}
i & =\arccos \left(\cos \Delta i_{r e f} \sin \gamma_{2}-\sin \Delta i_{r e f} \sin \psi_{m}^{\prime} \cos \gamma_{2}\right) \\
j & =q_{1}-\arctan \left(\frac{\sin \Delta i_{r e f} \sin \psi_{m}^{\prime} \sin \gamma_{2}+\cos \Delta i_{r e f} \cos \gamma_{2}}{\sin \Delta i_{r e f} \cos \psi_{m}^{\prime}}\right)
\end{aligned}
$$

Other machine-tool settings can be derived from the observation of Figure 5

$$
\begin{aligned}
\Delta X_{B 1} & =S_{r 2} \cos q_{2} \cos \gamma_{2}-r_{c} \sin \Delta i_{r e f} \sin \gamma_{2} \\
S_{r 1} & =\sqrt{S_{r 2}^{2} \sin ^{2} q_{2}+\left[S_{r 2} \cos q_{2} \sin \gamma_{2}+r_{c} \sin \Delta i_{r e f} \cos \gamma_{2}\right]^{2}} \\
q_{1} & =\arctan \left[\frac{S_{r 2} \sin q_{2}}{S_{r 2} \cos q_{2} \sin \gamma_{2}+r_{c} \sin \Delta i_{r e f} \cos \gamma_{2}}\right]
\end{aligned}
$$

The remaining machine-tool settings are not affected by the reference tilt angle $\Delta i_{r e f}$ and the modified mean spiral angle $\psi_{m}^{\prime}$. However, the blade pressure angles of the pinion head-cutter have to be updated when a reference tilt angle $\Delta i_{r e f}$ is applied. Figure 6 shows a portion of the pinion head-cutter where the front plane of the inner blade and its projected plane on the cut section A-A' are outlined. Whereas the blade pressure angle $\alpha_{b i}$ is measured on the front plane, the pressure angle $\alpha_{c i}$ is measured on the projected plane. A similar representation would be possible for the outer blade with its corresponding angles $\alpha_{b o}$ and $\alpha_{c o}$.

The new blade pressure angles $\alpha_{b i}^{\prime}$ and $\alpha_{b o}^{\prime}$ for the inner and outer blades of the pinion head-cutter are determined as follows: 


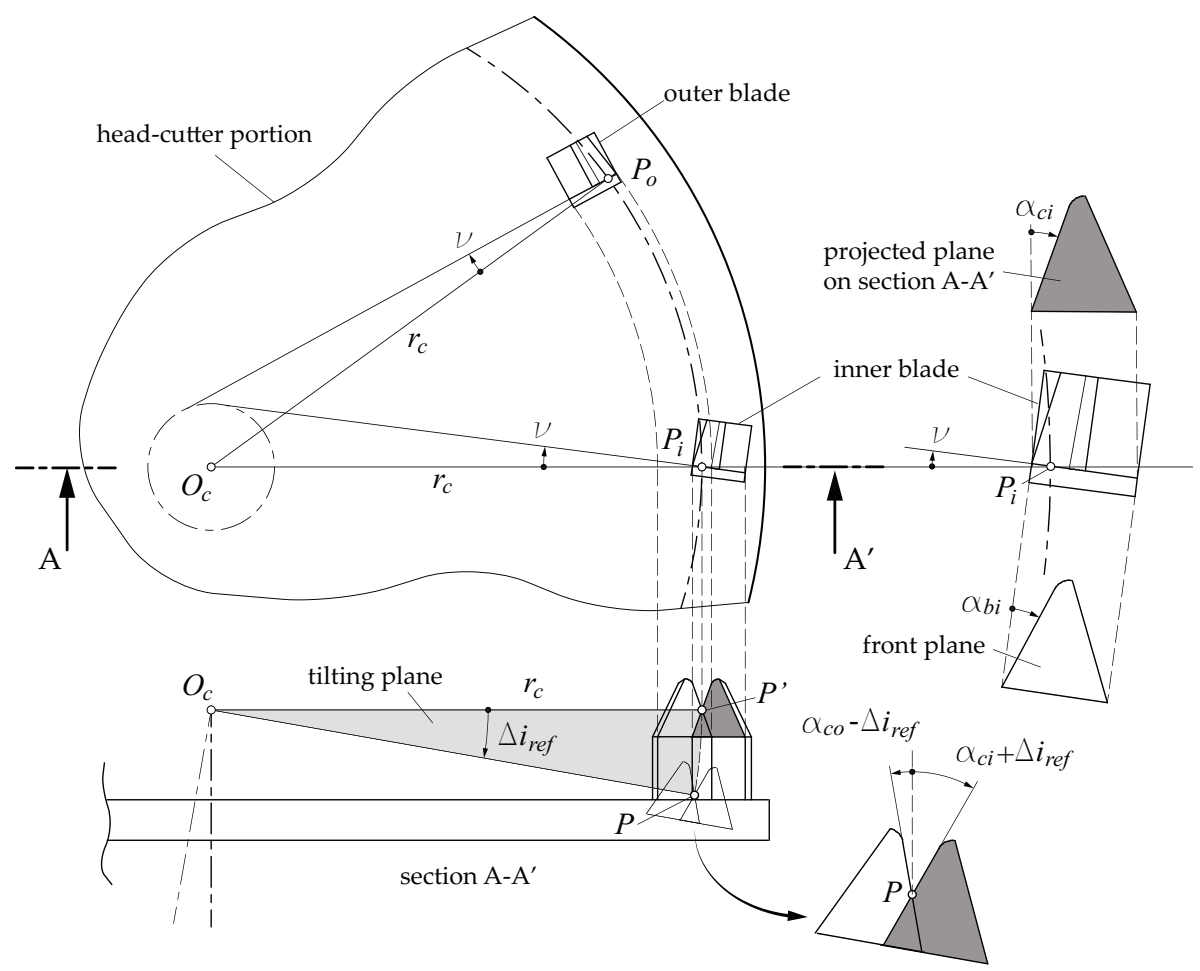

Figure 6: For determination of inner and outer blade pressure angles when a reference tilt angle $\Delta i_{r e f}$ is applied.

- It would be easy to prove that the blade pressure angles $\left(\alpha_{b i}, \alpha_{b o}\right)$ and the pressure angles $\left(\alpha_{c i}, \alpha_{c o}\right)$ are related through the slope angle $v$ as

$$
\begin{aligned}
\tan \alpha_{c i} & =\tan \alpha_{b i} \cos v \\
\tan \alpha_{c o} & =\tan \alpha_{b o} \cos v
\end{aligned}
$$

- Application of a reference tilt angle $\Delta i_{\text {ref }}$ implies that the pressure angles are modified for the pinion head-cutter as

$$
\begin{aligned}
\alpha_{c i}^{\prime} & =\alpha_{c i}+\Delta i_{r e f} \\
\alpha_{c o}^{\prime} & =\alpha_{c o}-\Delta i_{r e f}
\end{aligned}
$$

- In order to match the pinion head-cutter profiles with the gear head-cutter profiles and to match the pressure angles $\left(\alpha_{c i}^{\prime}, \alpha_{c o}^{\prime}\right)$ with those of the gear head-cutter (which is not tilted), it is required to decrease the inner pressure angle $\alpha_{c i}$ by the amount $\Delta i_{r e f}$ and to increase the outer pressure angle $\alpha_{c o}$ by the amount $\Delta i_{r e f}$. The new blade pressure angles are then determined as follows

$$
\begin{aligned}
\alpha_{b i}^{\prime} & =\arctan \left[\frac{\tan \left(\alpha_{c i}-\Delta i_{r e f}\right)}{\cos v}\right] \\
\alpha_{b o}^{\prime} & =\arctan \left[\frac{\tan \left(\alpha_{c o}+\Delta i_{r e f}\right)}{\cos v}\right]
\end{aligned}
$$

In the case of a hypoid gear drive, the machine-tool settings given by relations (24), (25) and (26) are modified as 
follows

$$
\begin{aligned}
S_{r 1} & =\sqrt{\left(S_{r 2} \sin q_{2}\right)^{2}+\left[S_{r 2} \cos q_{2} \sin \gamma_{2}+\left(\Delta X_{B 2}+r_{c} \sin \Delta i_{r e f}\right) \cos \gamma_{2}\right]^{2}} \\
q_{1} & =\arctan \left[\frac{S_{r 2} \sin q_{2}}{S_{r 2} \cos q_{2} \sin \gamma_{2}+\left(\Delta X_{B 2}+r_{c} \sin \Delta i_{r e f}\right) \cos \gamma_{2}}\right] \\
\Delta X_{B 1} & =S_{r 2} \cos q_{2} \cos \gamma_{2}-\left(\Delta X_{B 2}+r_{c} \sin \Delta i_{r e f}\right) \sin \gamma_{2}-p_{2}
\end{aligned}
$$

The procedure to obtain swivel angle $j$ and tilt angle $i$ is exactly the same as the one described for a spiral bevel gear drive. The resulting values are the same as those given in relations (49) and (50). The blade pressure angles for the pinion head-cutter are determined in the same way as well and their values are given by relations (58) and (59).

\section{Longitudinal crowning of the pinion tooth surfaces through application of modified roll}

Application of modified roll in a face-hobbing process requires especial attention since both tooth sides are cut simultaneously and a continuous non-indexing process requires the use of a periodic function. In the other hand, a continuous function in a given interval of its independent variable can be converted into a periodic one through its development through the Fourier series [18]. Consider the generalized parameter of generation of the pinion, $\psi_{1}$ (see Figure 7), as a function of the rotation of the cradle $\psi_{c r}$ and the rotation of the head-cutter $\theta_{c}$

$$
\psi_{1}=\frac{N_{2}}{N_{1}} \psi_{c r}+\frac{N_{b}}{N_{1}} \theta_{c}
$$

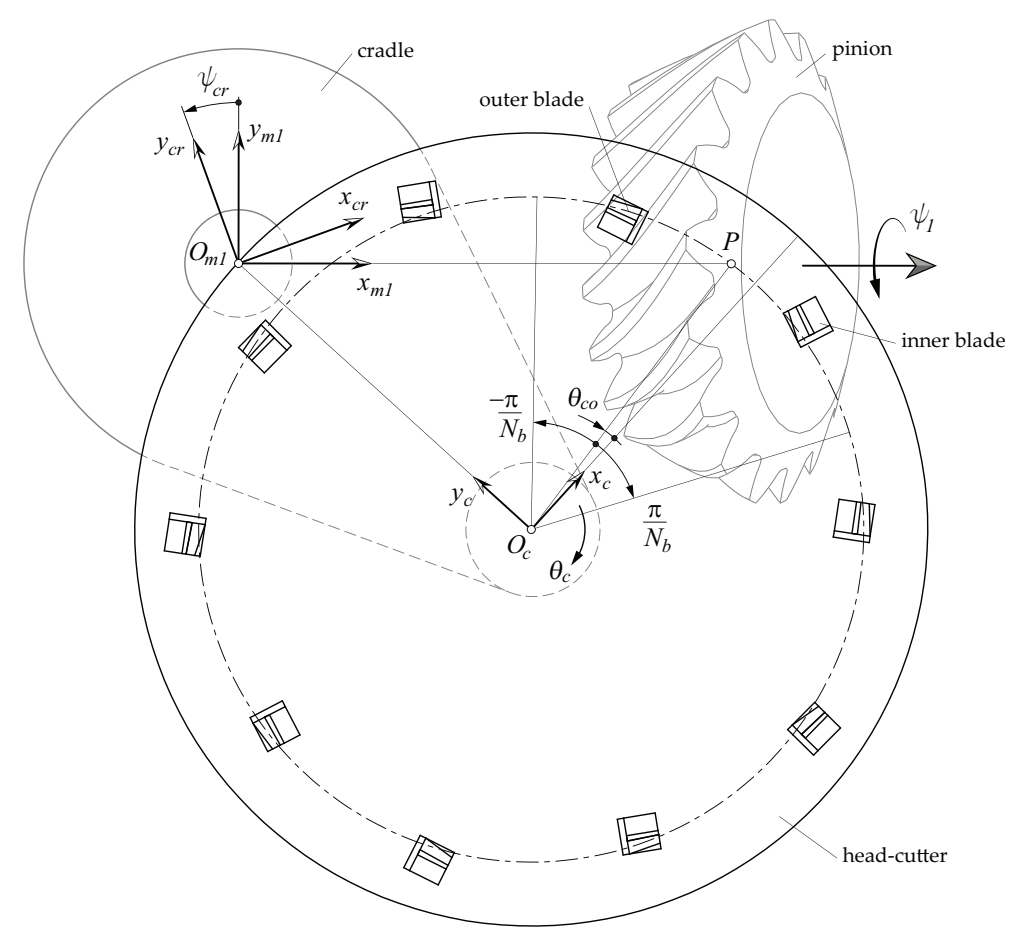

Figure 7: For illustration of angles $\psi_{1}$ of the pinion, $\psi_{c r}$ of the cradle, and $\theta_{c}$ of the head-cutter.

Rotations of the head-cutter and the pinion can be roll modified based on the application of a parabolic function. This function is named here as gear-to-blade roll function. Actually, a parabolic function in the interval 
$\left[\theta_{c o}-\frac{\pi}{N_{b}}, \theta_{c o}+\frac{\pi}{N_{b}}\right]$ is required for each tooth side

$$
\begin{aligned}
& \Delta \psi_{1, g b}^{(c v)}=+\Delta \Psi_{g b}^{(c v)} \frac{N_{b}^{2}}{\pi^{2}}\left(\theta_{c}-\theta_{c o}^{(c v)}\right)^{2} \\
& \Delta \psi_{1, g b}^{(c c)}=-\Delta \Psi_{g b}^{(c c)} \frac{N_{b}^{2}}{\pi^{2}}\left(\theta_{c}-\theta_{c o}^{(c c)}\right)^{2}
\end{aligned}
$$

Here, the superscript $(c v)$ refers to the convex side whereas the superscript $(c c)$ refers to the concave side. Subindex $(\mathrm{gb})$ refers to gear-to-blade roll. $\Delta \Psi_{g b}$ is a given value of the functions at the extremes of the above mentioned interval and $\theta_{c o}$ is a reference angle for the rotation of the head-cutter (see Figure 7).

The functions given in (64) and (65) are continuous but not periodic. In order to obtain a periodic function with period $\frac{2 \pi}{N_{b}}$, approximations to those above mentioned functions with a two-term Fourier series are considered instead

$$
\begin{aligned}
\Delta \psi_{1, g b}^{(c v, F)} & =-\frac{\Delta \Psi_{g b}^{(c v)}}{8}\left\{4 \cos \left[\left(\theta_{c}-\theta_{c o}^{(c v)}\right) N_{b}\right]-\cos \left[2\left(\theta_{c}-\theta_{c o}^{(c v)}\right) N_{b}\right]\right\}+\frac{3 \Delta \Psi_{g b}^{(c v)}}{8} \\
\Delta \psi_{1, g b}^{(c c, F)} & =+\frac{\Delta \Psi_{g b}^{(c c)}}{8}\left\{4 \cos \left[\left(\theta_{c}-\theta_{c o}^{(c c)}\right) N_{b}\right]-\cos \left[2\left(\theta_{c}-\theta_{c o}^{(c c)}\right) N_{b}\right]\right\}-\frac{3 \Delta \Psi_{g b}^{(c c)}}{8}
\end{aligned}
$$

Figure 8 shows the non-periodic parabolic functions $\Delta \psi_{1, g b}^{(c v)}$ and $\Delta \psi_{1, g b}^{(c c)}$, and the periodic two-term Fourier series $\Delta \psi_{1, g b}^{(c v, F)}$ and $\Delta \psi_{1, g b}^{(c c, F)}$. Application of functions

$$
\begin{aligned}
& \psi_{1}^{(c v)}=\frac{N_{2}}{N_{1}} \psi_{c r}+\frac{N_{b}}{N_{1}} \theta_{c}+\Delta \psi_{1, g b}^{(c v, F)} \\
& \psi_{1}^{(c c)}=\frac{N_{2}}{N_{1}} \psi_{c r}+\frac{N_{b}}{N_{1}} \theta_{c}+\Delta \psi_{1, g b}^{(c c, F)}
\end{aligned}
$$

would allow its own crowning to be applied at each tooth side. This method would require two processes, one for the convex side and another one for the concave side, and is feasible since crowning of the convex side does not affect to the concave side and viceversa. This circumstance will be proved below.

Actually, a Fourier series with any other number of terms (one, three, four, ...) would be possible to implement. The reason why a two-term function was chosen here among other n-term functions is because this function is the one that keeps a flat portion during a larger interval of the independent variable and drops closer to the extremes of the interval, intensifying the crowning at both tooth ends.

\section{Numerical examples}

Two cases of design are considered here: a spiral bevel gear drive and a hypoid gear drive. Table 1 shows the basic transmission and cutter data corresponding to each case of design.

Blank data for pinion and gear can be obtained at each case of design through application of Standard ANSI/AGMA 2005-D03 [17]. The suggested coefficients for the definition of the tooth height, addendum and dedendum are illustrated in Table 2. Here, for the spiral bevel gear drive, the mean addendum factor $c_{1}$ is chosen in order to have the same addendum in pinion and gear, not following the suggestion of the standard that invites to chose a larger addendum in the pinion to avoid undercutting. Such undercutting is not observed in the geometric models. The suggestion for $c_{1}$ has been followed in the case of the hypoid gear drive. The resulting blank data are illustrated in Table 3 .

\subsection{Conjugated action}

In order to get conjugated action in the two examples of gear drives, it is necessary that the profiles of the inner blades (respectively, the outer blades) of the pinion head-cutter match the profiles of the outer blades (respectively, the inner blades) of the gear head-cutter. The blade module $m_{b}$ of the head-cutter is obtained as the mean normal module of the corresponding gear drive. The reference height $h_{r}$ is considered as the mean dedendum in the case of the spiral 

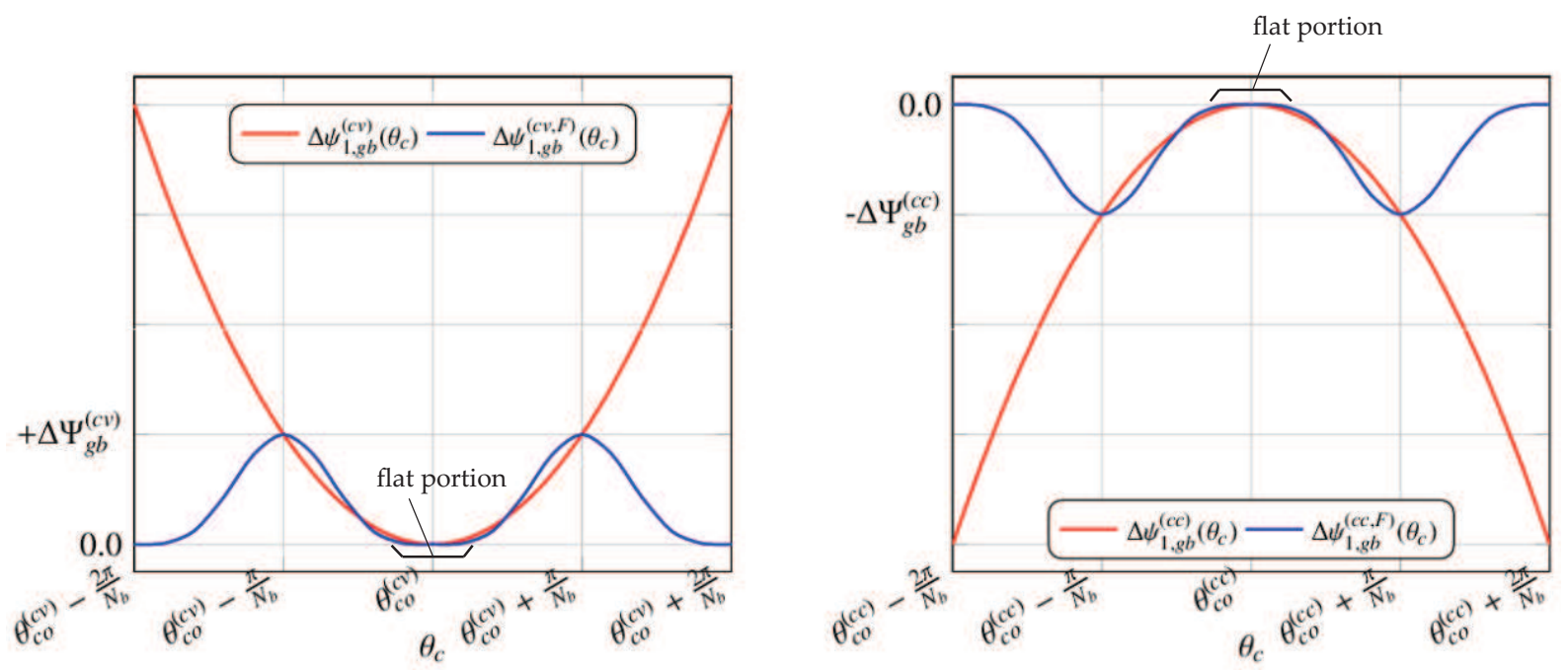

Figure 8: Illustration of non-periodic parabolic function $\Delta \psi_{1, g b}\left(\theta_{c}\right)$ and periodic two-term Fourier series $\Delta \psi_{1, g b}^{(F)}\left(\theta_{c}\right)$ for convex tooth side (left) and concave tooth side (right).

Table 1: Basic transmission and cutter data.

\begin{tabular}{lcc}
\hline Data & spiral gear drive & hypoid gear drive \\
\hline Reference gear ratio & 2.25 & 5.0 \\
Shaft angle $\left[{ }^{\circ}\right.$ ] & 90.0 & 90.0 \\
Pinion offset [mm] & Not Applicable & 15.0 (below center line) \\
Input power [kW] & 80.0 & 100.0 \\
Pinion speed [rpm] & 1440.0 & 1200.0 \\
Gear mean spiral angle $\left[^{\circ}\right.$ ] & 40.0 & Not applicable as input \\
Gear hand of spiral & right-hand & right-hand \\
Cutter radius [mm] & 62.0 & 110.0 \\
Number of blade groups & 5 & 9 \\
\hline
\end{tabular}

bevel gear drive and as the value given by (23) in the case of the hypoid gear drive. The slope angles for the assembly of the blades at the head-cutters are obtained as (see [9])

$$
v=\arcsin \frac{m_{b} N_{b}}{2 r_{c}}
$$

The blade pressure angles are taken as 20 degrees for the spiral bevel gear drive and are derived following the directions of the Standard ANSI/AGMA 2005-D04 in the case of the hypoid gear drive starting form a reference pressure angle of 20 degrees. Table 4 summarizes the main data of the head cutters. The nomenclature that is followed here is the same as the one presented in [9], where a mathematical model for a more general face-hobbing process, the Cyclo-palloid system, is comprehensively explained including blade equations and matrix transformations that govern the machining positions.

The basic machine-tool settings of the gear are derived using the relations given in Section 2. Such basic machinetool settings are shown in Table 5.

Derivation of basic machine-tool settings of the pinion can be done through the procedure proposed in Section 2. Application of relations from (3) to (32) provide the basic machine-tool settings that are illustrated in Table 6.

Figure 9 shows the spiral bevel and the hypoid gear drives that result from application of the basic machine-tool settings that are illustrated in Tables 5 and 6 . Line contact is observed. Perfect conjugated action is obtained since no 
Table 2: ANSI/AGMA 2005-D03 factors.

\begin{tabular}{lcc}
\hline Data & spiral gear drive & hypoid gear drive \\
\hline Depth factor, $k_{1}$ & 2.0 & 2.0 \\
Mean addendum factor, $c_{1}$ & $0.5^{*}$ & 0.2216 \\
Clearance factor, $k_{2}$ & 0.1 & 0.125 \\
Circular thickness factor, $k_{3}$ & 0.072 & 0.1568 \\
\hline * Does not follow the suggestion of Standard ANSI/AGMA 2005-D03 [17]
\end{tabular}

Table 3: Blank data.

\begin{tabular}{|c|c|c|c|c|}
\hline Blank data & spiral pinion & spiral gear & hypoid pinion & hypoid gear \\
\hline Tooth number & $N_{1}=17$ & $N_{2}=38$ & $N_{1}=12$ & $N_{2}=58$ \\
\hline Pitch angle $\left[{ }^{\circ}\right]$ & $\gamma_{1}=24.102$ & $\gamma_{2}=65.898$ & $\gamma_{1}=14.177$ & $\gamma_{2}=75.751$ \\
\hline Mean spiral angle $\left[{ }^{\circ}\right]$ & \multicolumn{2}{|c|}{$\psi_{m}=40.0$} & $\psi_{m 1}=40.003$ & $\psi_{m 2}=34.163$ \\
\hline Hand of spiral & left-hand & right-hand & left-hand & right-hand \\
\hline Outer transverse module [mm] & \multicolumn{2}{|c|}{$m_{o t}=4.972$} & \multirow{2}{*}{\multicolumn{2}{|c|}{$\begin{array}{c}m_{o t}=5.804 \\
m_{m n}=4.083\end{array}$}} \\
\hline Mean normal module [mm] & \multicolumn{2}{|c|}{$m_{m n}=3.312$} & & \\
\hline Mean cone distance [mm] & \multirow{2}{*}{\multicolumn{2}{|c|}{$\begin{array}{c}A_{m}=89.9883 \\
F_{w}=27.0\end{array}$}} & $A_{m 1}=178.329$ & $A_{m 2}=147.654$ \\
\hline Face width $[\mathrm{mm}]$ & & & $F_{w 1}=53.572$ & $F_{w 2}=52.0$ \\
\hline Outer addendum [mm] & $a_{01}=3.312$ & $a_{02}=3.312$ & $a_{01}=6.299$ & $a_{02}=1.868$ \\
\hline Outer dedendum [mm] & $b_{01}=3.974$ & $b_{02}=3.974$ & $b_{01}=2.889$ & $b_{02}=7.320$ \\
\hline Face cone angle $\left[{ }^{\circ}\right]$ & $\gamma_{F 1}=24.102$ & $\gamma_{F 2}=65.898$ & $\gamma_{F 1}=14.177$ & $\gamma_{F 2}=75.751$ \\
\hline Root cone angle $\left[{ }^{\circ}\right]$ & $\gamma_{R 1}=24.102$ & $\gamma_{R 2}=65.898$ & $\gamma_{R 1}=14.177$ & $\gamma_{R 2}=75.751$ \\
\hline Pitch apex beyond crossing point [mm] & \multicolumn{2}{|c|}{ Not Applicable } & $p_{1}=-15.775$ & $p_{2}=4.364$ \\
\hline
\end{tabular}

unloaded transmission errors occur.

\subsection{Crowning through the tilt angle}

A reference tilt angle $\Delta i_{r e f}$ and an additional reference mean spiral angle $\Delta \psi_{m, r e f}$ (see Section 4) are considered for application of crowning in the pinion tooth surfaces. Magnitude $\Delta i_{r e f}$ controls the amount of crowning whereas magnitude $\Delta \psi_{m, r e f}$ moves the central position of the crowning along the face width. Since the same variables are applied for both tooth sides, centering of the crowning can be obtained successfully for just one tooth side. Table 7 shows the values applied for the spiral pinion and the hypoid pinion where centering of the crowning is sought for the pinion convex tooth side.

Applications of relations given in Section 4 provides the new basic machine-tool settings for the spiral pinion and the hypoid pinion that are illustrated in Table 8. Some pinion cutter data need modifications as the outer and inner blade pressure angles that are also shown in Table 8.

Figure 10 shows the comparison of the pinion tooth surfaces where surface $\Sigma_{r e f}$ corresponds to the one obtained to get conjugate action with the gear tooth surface and surface $\Sigma_{t}$ corresponds to the crowned one by tilting the headcutter. The crowning is centered at the convex tooth side of the spiral pinion for the values shown in Table 7, but it is not centered at the concave tooth side. Figure 10 shows as well the effects of a decrement of the reference additional mean spiral angle in 0.07 degrees, which helps centering the crowning at the concave tooth side but it loses the centering position of the crowning at the convex tooth side. A similar behavior can be observed in the hypoid pinion.

As a result of the crowning, the contact pattern will be localized with a bias close to zero when the convex tooth side of the pinion is driving. This circumstance can be observed in Figure 11 for the spiral bevel and the hypoid gear drives, where some unloaded transmission errors are shown as well. Although it is not illustrated in Figure 11, the 

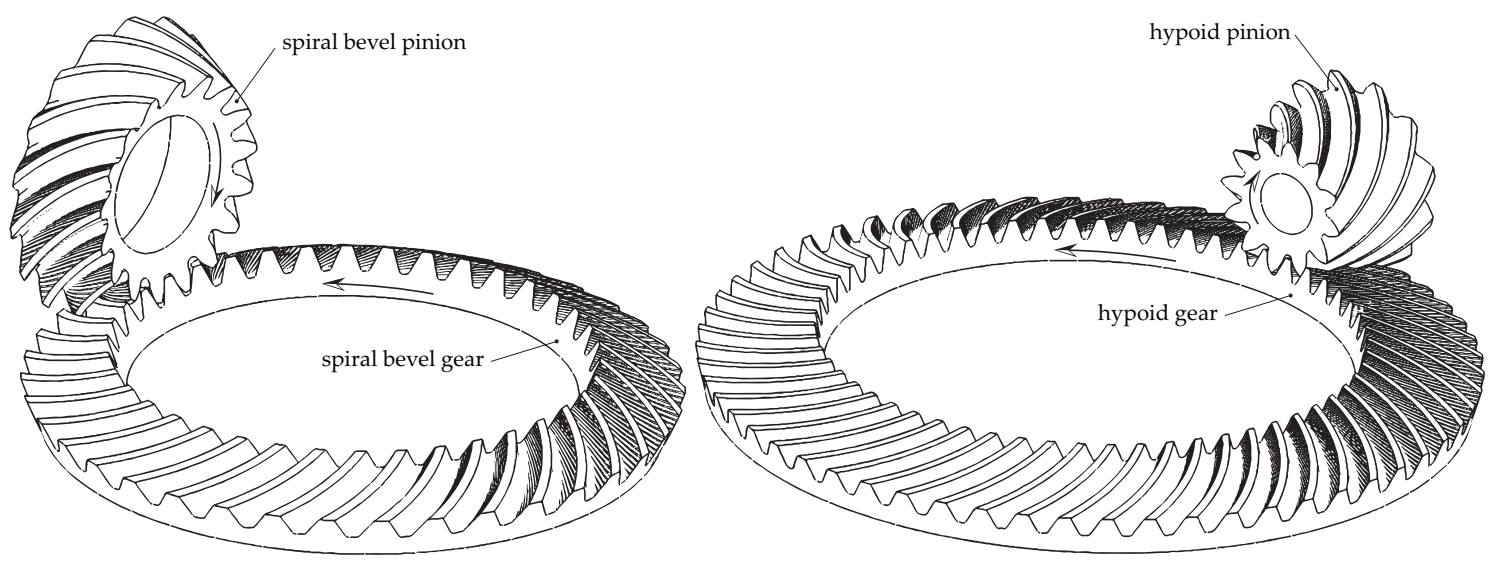

Figure 9: Illustration of the spiral bevel and the hypoid gear drives with line contact.

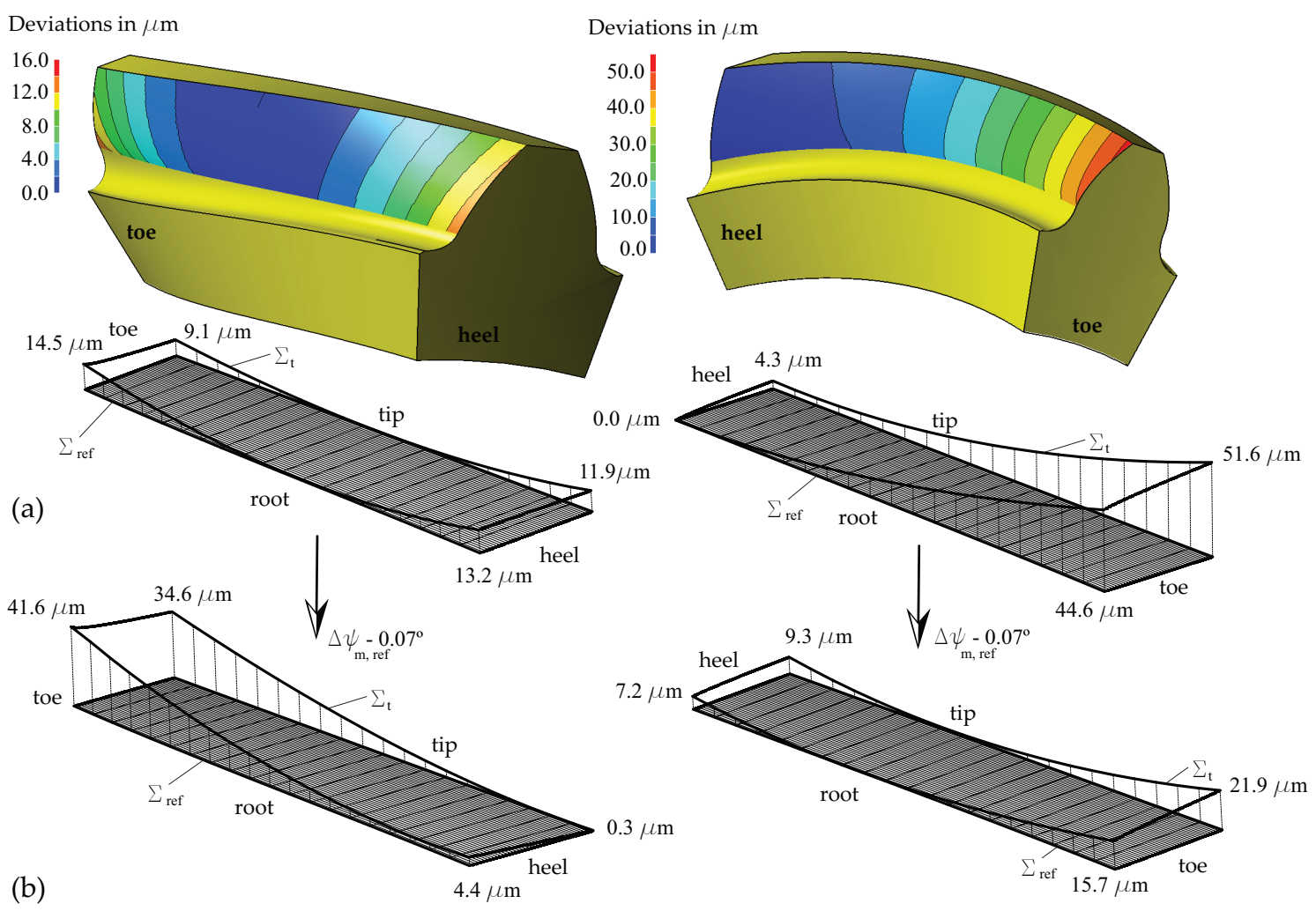

Figure 10: Geometry comparison between the spiral bevel pinion tooth surface for conjugated action, $\Sigma_{r e f}$, and the crowned one, $\Sigma_{t}$, through: (a) $\Delta i_{r e f}=1.0$ degrees and $\Delta \psi_{m, r e f}=0.045$ degrees, and (b) $\Delta i_{r e f}=1.0$ degrees and $\Delta \psi_{m, r e f}=0.045-0.07$ degrees. 
Table 4: Main data of the head cutters.

\begin{tabular}{|c|c|c|}
\hline & spiral gear drive & hypoid gear drive \\
\hline Main data & pinion cutter gear cutter & pinion cutter gear cutter \\
\hline Blade module [mm] & $m_{b}=3.312$ & $m_{b}=4.083$ \\
\hline Reference height [mm] & $h_{r}=3.974$ & $h_{r}=5.104$ \\
\hline Point inner radius [mm] & $r_{c i}=62.0$ & $r_{c i}=110.0$ \\
\hline Point outer radius $[\mathrm{mm}]$ & $r_{c o}=62.0$ & $r_{c o}=110.0$ \\
\hline Slope angle $\left[{ }^{\circ}\right]$ & $v=7.674$ & $v=11.781$ \\
\hline Inner blade pressure angle $\left[{ }^{\circ}\right]$ & $\alpha_{b i}=20.0$ & $\alpha_{b i}=20.097 \quad \alpha_{b i}=19.903$ \\
\hline Outer blade pressure angle $\left[^{\circ}\right]$ & $\alpha_{b o}=20.0$ & $\alpha_{b o}=19.903$ \\
\hline
\end{tabular}

Table 5: Basic machine-tool settings for the spiral bevel gear and the hypoid gear.

\begin{tabular}{lcc}
\hline Basic machine-tool settings & spiral gear & hypoid gear \\
\hline Radial distance [mm] & $S_{r 2}=116.725$ & $S_{r 2}=142.851$ \\
Cradle angle $\left[^{\circ}\right]$ & $q_{2}=-42.670$ & $q_{2}=-44.462$ \\
Machine center to back [mm] & $\Delta X_{D 2}=0.0$ & Not Applicable \\
Machine center to crossing point [mm] & Not Applicable & $\Delta X_{C 2}=4.364$ \\
Sliding base [mm] & $\Delta X_{B 2}=0.0$ & $\Delta X_{B 2}=-2.216$ \\
Machine root angle [ $\left.{ }^{\circ}\right]$ & $\gamma_{m 2}=65.898$ & $\gamma_{m 2}=75.751$ \\
Gear-to-cradle roll ratio & Not Applicable & Not Applicable \\
Gear-to-blade roll ratio & $m_{2 b}=0.1316$ & $m_{2 b}=0.1552$ \\
\hline
\end{tabular}

contact pattern is shifted towards the heel when the concave tooth side of the pinion is driving. These results show that this type of crowning is only effective when just one direction of rotation is operating.

\subsection{Crowning through modified gear-to-blade roll}

Crowning through modified gear-to-blade roll has been applied as it is explained in Section 5 using the values shown in Table 9. These values are found by trial and error until an appropriate crowning is found on both tooth sides of the pinion. The basic machine-tool settings are the same as those applied to get conjugate action (see Table 6). Figure 12 shows a geometry comparison between the reference tooth surface to get conjugate action and the one obtained through modified gear-to-blade roll using the values shown in Table 9 for the spiral bevel pinion. It is shown that both tooth sides of the pinion are provided with a centered crowning. Similar results are obtained for the hypoid pinion. Figure 13 shows the contact patterns for both sides of rotation in the spiral bevel gear drive and the hypoid gear drive. No unloaded transmission errors appear for this type of crowning.

Since this type of crowning requires two operations, one for the convex tooth side and another one for the concave tooth side, it is important to check that finishing of the convex tooth side does not affect to the final surface of the concave tooth side, and viceversa. Figure 14 shows geometry comparisons of surface $\Sigma_{c v}$ with surface $\Sigma_{c v}^{*}$ and of surface $\Sigma_{c c}$ with surface $\Sigma_{c c}^{*}$. Here, surfaces $\Sigma_{c v}$ and $\Sigma_{c c}$ are the final tooth surfaces obtained through the parameters shown in Table 9. Surface $\Sigma_{c v}^{*}$ is the tooth surface of the convex side when finishing of the concave tooth side is taking place. Surface $\Sigma_{c c}^{*}$ is the tooth surface of the concave side when finishing of the convex tooth side is taking place. Surface $\Sigma_{c v}^{*}$ is over surface $\Sigma_{c v}$ and this means that finishing of the concave tooth side (when surface $\Sigma_{c v}^{*}$ is generated) does not undercut the final convex tooth surface. In the same way, surface $\Sigma_{c c}^{*}$ is over surface $\Sigma_{c c}$ and this means that finishing of the convex tooth side (when surface $\Sigma_{c c}^{*}$ is generated) does not undercut the final concave tooth surface.

\subsection{Adjusting the bearing contact}

A contact pattern with a bias close to zero as the ones obtained either through application of a tilt angle or application of modified gear-to-blade roll can caused edge contact at the tip. Application of circular or parabolic 

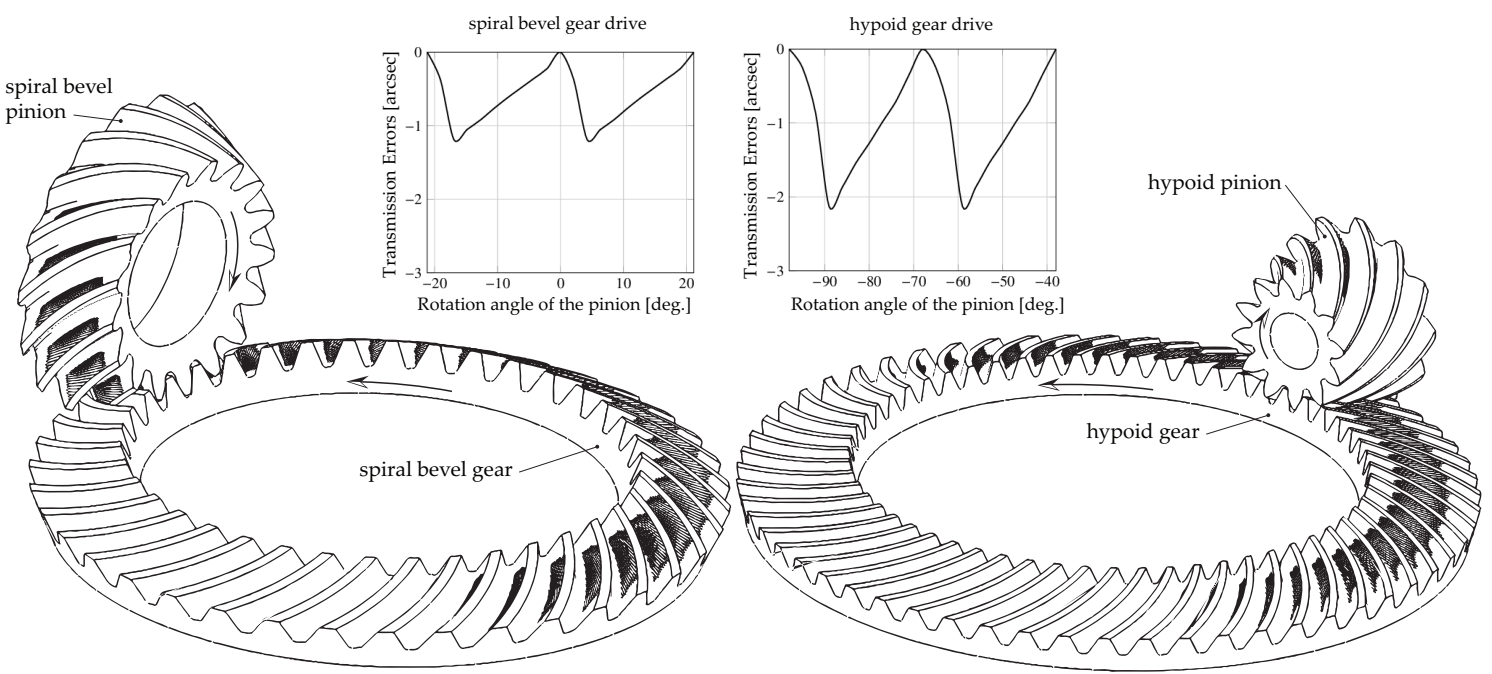

Figure 11: Illustration of the spiral bevel and the hypoid gear drives with localized bearing contact due to tilt crowning.
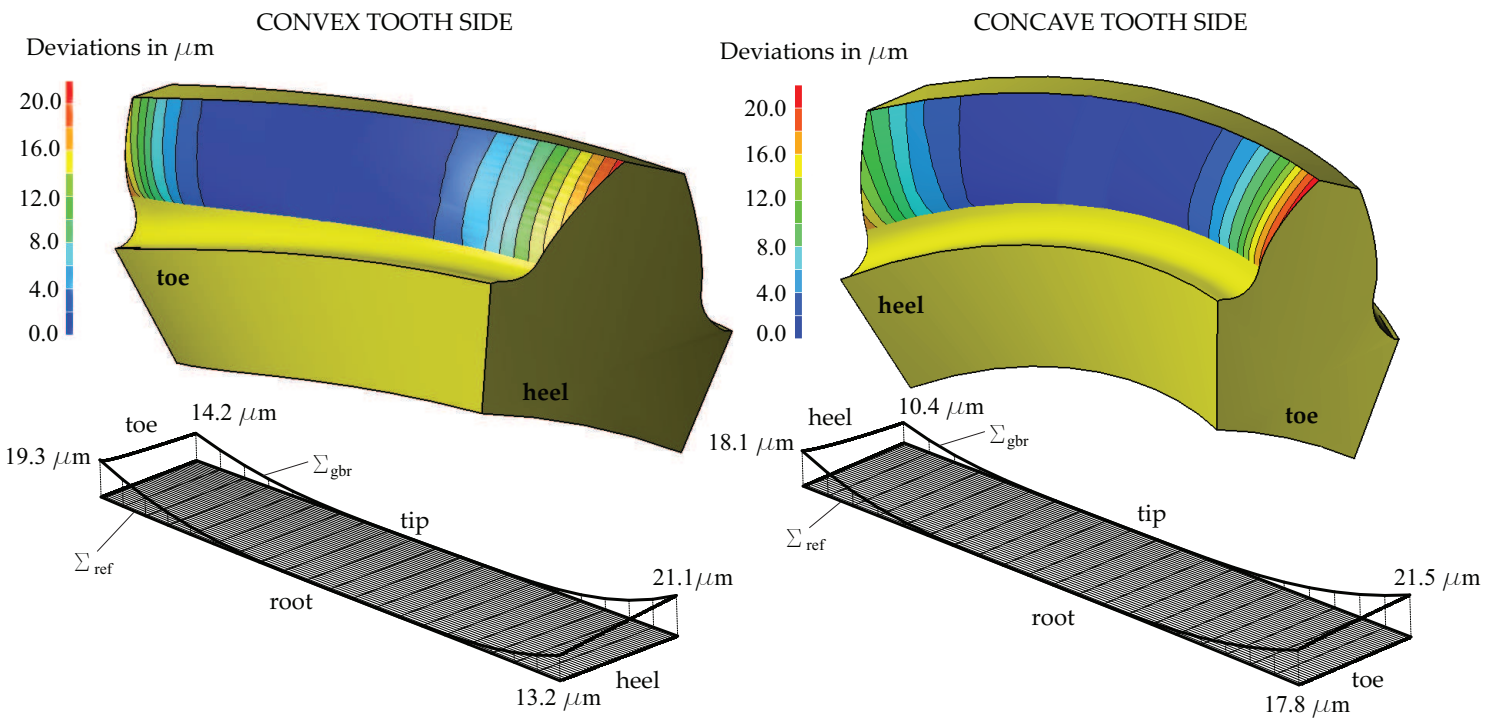

Figure 12: Geometry comparison between the spiral bevel pinion tooth surface for conjugated action, $\Sigma_{r e f}$, and the crowned one, $\Sigma_{g b r}$, through application of modified gear-to-blade roll using the values shown in Table 9. 


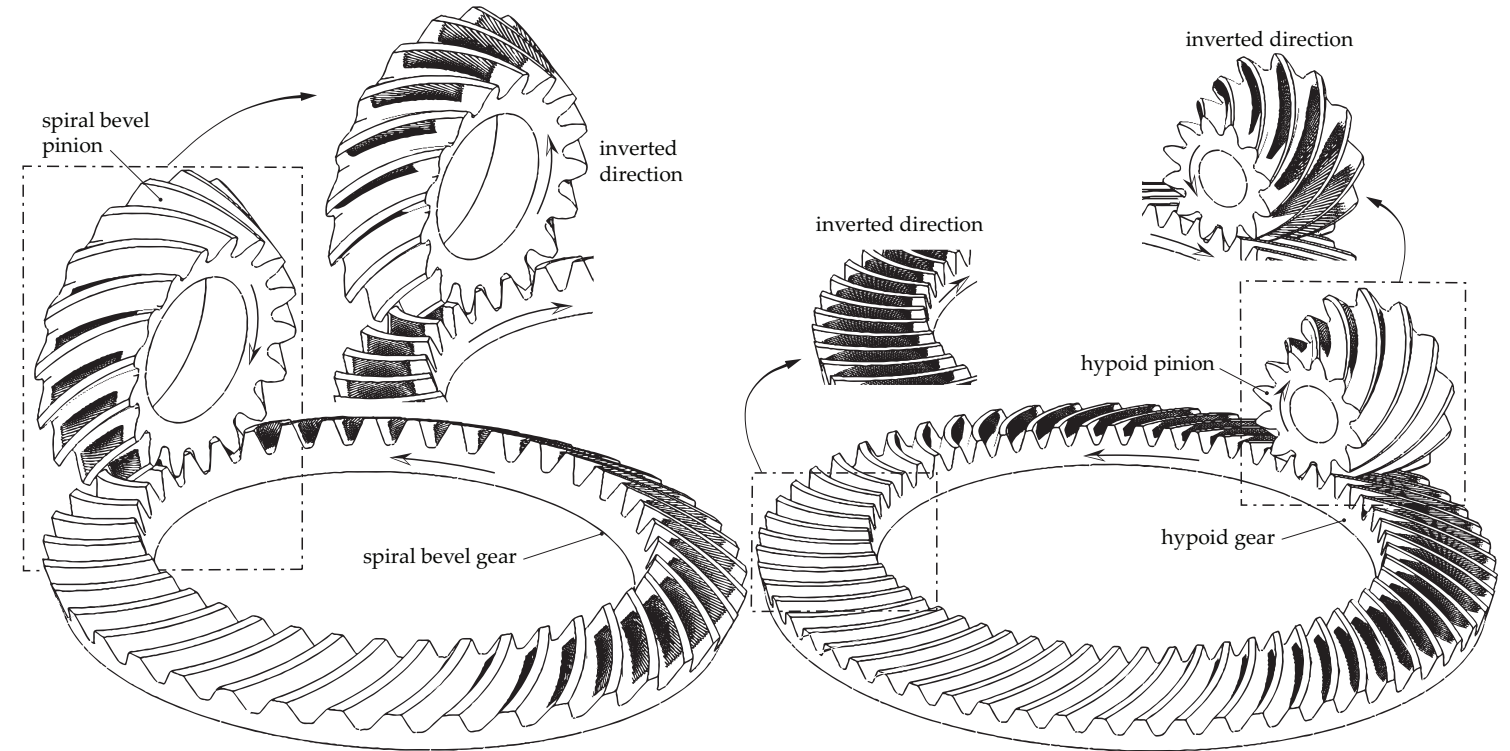

Figure 13: Illustration of contact patterns for both directions of rotation in the spiral bevel and the hypoid gear drives where the bearing contact is localized through modified gear-to-blade roll.
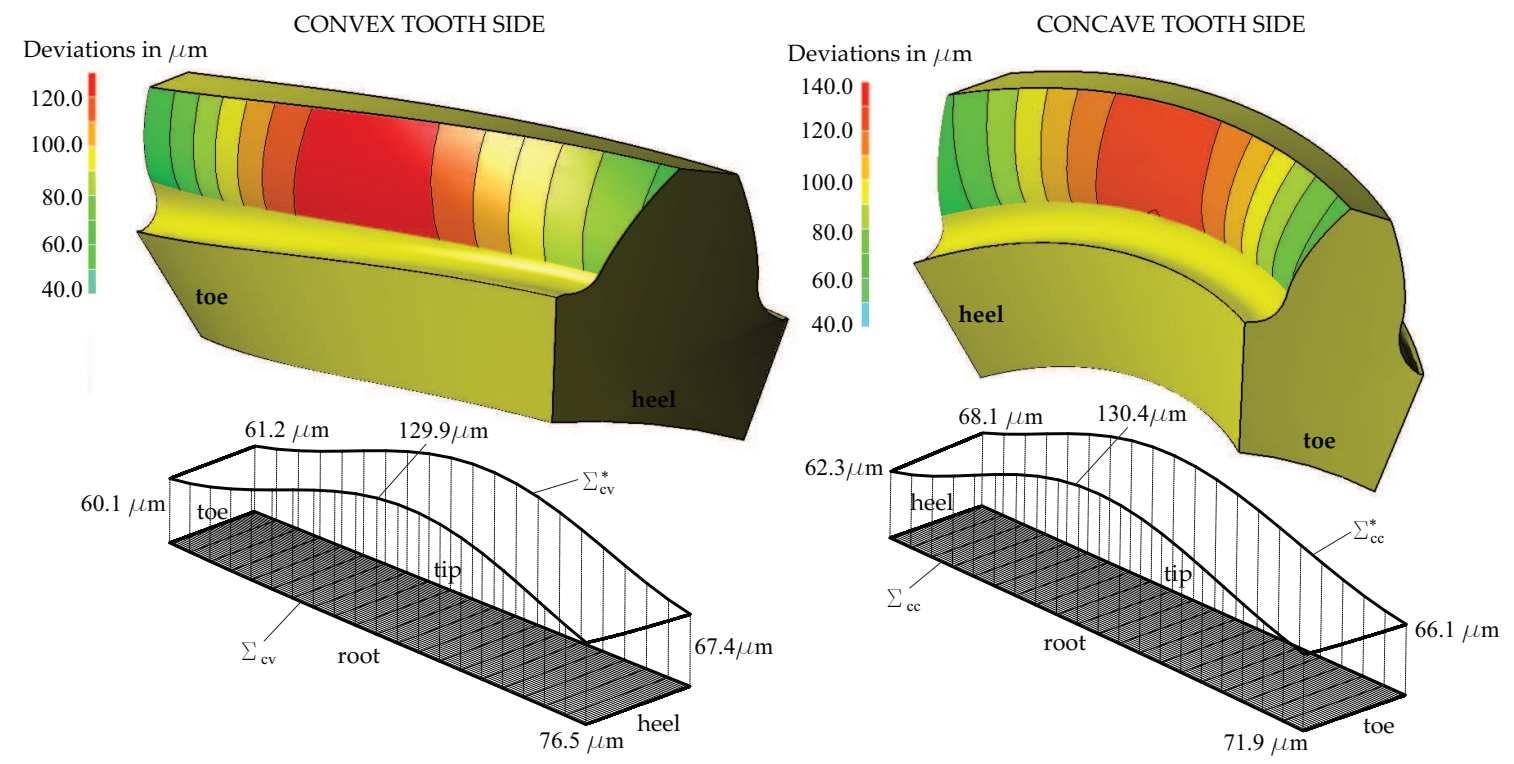

Figure 14: Geometry comparison of the spiral bevel pinion tooth surface $\Sigma_{c v}$ with $\Sigma_{c v}^{*}$ and tooth surface $\Sigma_{c c}$ with $\Sigma_{c c}^{*}$. 
Table 6: Basic machine-tool settings for the spiral bevel pinion and the hypoid pinion.

\begin{tabular}{lcc}
\hline Basic machine-tool settings & spiral pinion & hypoid pinion \\
\hline Radial distance [mm] & $S_{r 1}=73.732$ & $S_{r 1}=140.246$ \\
Cradle angle [ ${ }^{\circ}$ ] & $q_{1}=45.281$ & $q_{1}=45.516$ \\
Machine center to back [mm] & $\Delta X_{D 1}=0.0$ & Not Applicable \\
Machine center to crossing point [mm] & Not Applicable & $\Delta X_{C 1}=0.0$ \\
Sliding base [mm] & $\Delta X_{B 1}=23.209$ & $\Delta X_{B 1}=22.878$ \\
Blank offset [mm] & $\Delta X_{E 1}=0.0$ & $\Delta X_{E 1}=-15.0$ \\
Machine root angle $\left[^{\circ}\right.$ ] & $\gamma_{m 1}=0.0$ & $\gamma_{m 1}=0.0$ \\
Tilt angle $\left[{ }^{\circ}{ }^{\circ}\right.$ & $i_{1}=24.102$ & $i_{1}=14.249$ \\
Swivel angle $\left[{ }^{\circ}\right.$ ] & $j_{1}=-44.719$ & $j_{1}=-44.484$ \\
Gear-to-cradle roll ratio & $m_{1 c}=2.2353$ & $m_{1 c}=4.8333$ \\
Gear-to-blade roll ratio & $m_{1 b}=0.2941$ & $m_{1 b}=0.7500$ \\
\hline
\end{tabular}

Table 7: Reference tilt and additional mean spiral angles.

\begin{tabular}{lcc}
\hline Data & spiral pinion & hypoid pinion \\
\hline Reference tilt angle, $\Delta i_{\text {ref }}\left[{ }^{\circ}\right]$ & 1.0 & 1.0 \\
Reference additional mean spiral angle, $\Delta \psi_{\text {m,ref }}\left[{ }^{\circ}\right]$ & 0.045 & 0.1 \\
\hline
\end{tabular}

profiles in the blades is a common procedure to modify the bias of the contact pattern. Application of bottom reliefs with circular or parabolic curves is another usual procedure to avoid edge contact. Application of parabolic or circular profiles in the whole blade profile or just on the bottom side of it has been presented in previous works $[9,10,15]$.

Figure 15 shows the contact pattern in a spiral bevel gear drive and a hypoid gear drive where crowning through application of modified gear-to-blade roll has been applied. Bottom relief has been applied as well either at the blades of the head-cutter that generates the pinion or the blades of the head-cutter that generates the gear. A parabolic profile has been considered at the bottom side of the blade with a parabola coefficient of $0.001 \mathrm{~mm}^{-1}$ and a height of bottom relief of $3.0 \mathrm{~mm}$ for generation of pinion and gear in the spiral bevel gear drive. In the case of the hypoid gear drive, the same values were considered in the pinion, but a larger value was considered in the gear for the parabola coefficient $\left(0.01 \mathrm{~mm}^{-1}\right)$. The basic machine-tool settings are the same as those applied in the previous section. As a consequence of the bottom relief, some unloaded transmission errors are observed.

\subsection{Compensating errors of alignment}

The bearing contact obtained in the previous section may be shifted when errors of alignment are present. Such errors can be due to shaft deflections when the design load is transmitted. Imagine that the set of alignment errors illustrated in Table 10 are present for the spiral bevel gear drive and the hypoid gear drive, for both directions of rotation (pinion in counterclockwise rotation and pinion in clockwise rotation) and for a given design load. Such errors could be obtained from a finite element analysis of the gear drives where the pinion and gear shafts are included into the finite element model. This analysis is out of the scope of this paper and can be refered to [19] for further investigation on derivation of alignment errors from a design load.

Figure 16 shows the shift of the bearing contact in both types of gear drives when the convex tooth side of the pinion teeth is driving and the errors of alignment that are illustrated in Table 10 for counterclockwise rotation of the pinion are present. Edge contacts and an increment of the level of transmission errors are observed in Figure 16 respect to those illustrated in Figure 15. The pinion and gear tooth geometries are the same in Figure 15 and Figure 16. Edge contact and an increment of transmission errors occur since alignment errors are not compensated. A different shift (not illustrated here) occurs when the concave tooth side of the pinion teeth is driving and the errors of alignment that are illustrated in Table 10 for clockwise rotation of the pinion are present. 


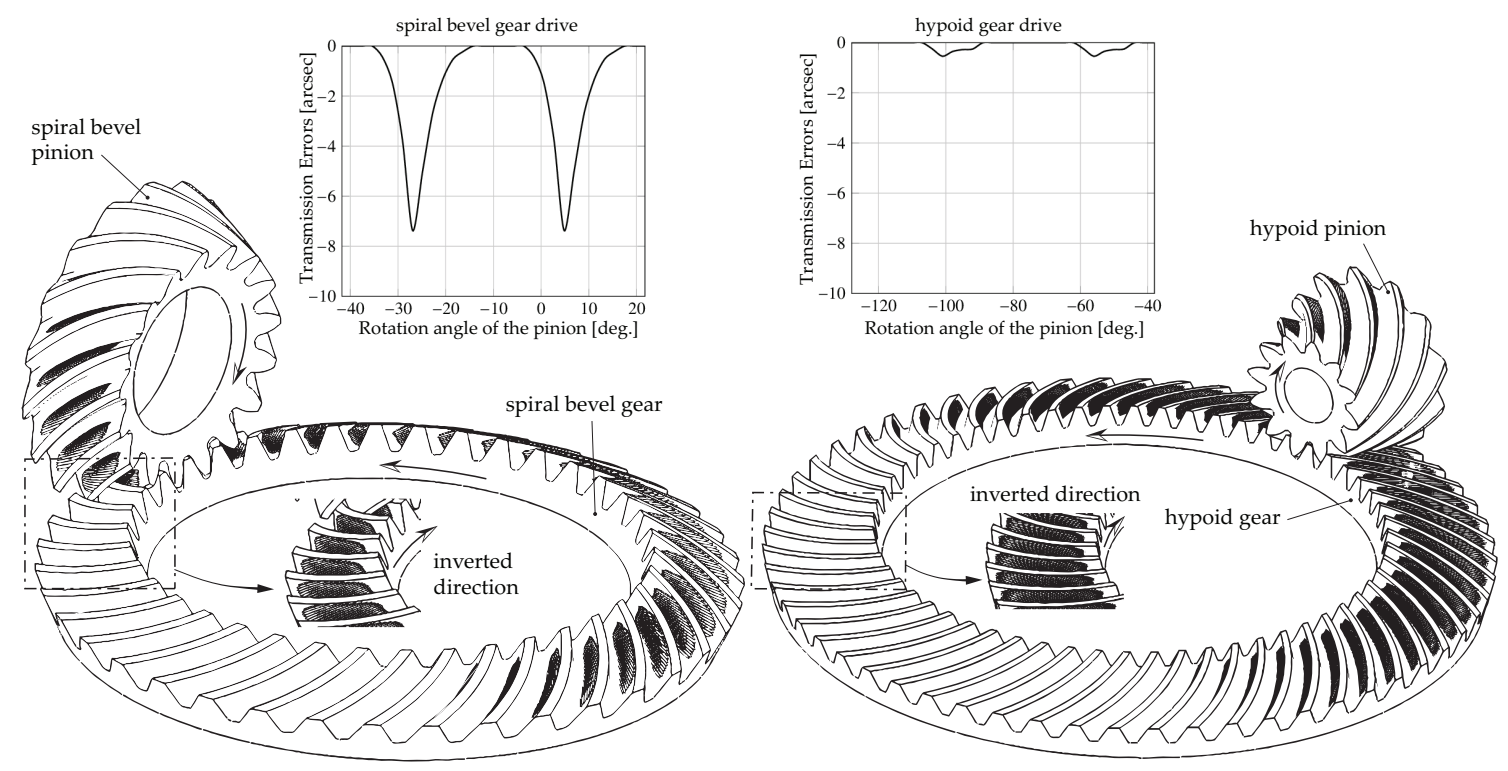

Figure 15: Illustration of contact patterns and transmission errors in the spiral bevel and the hypoid gear drives where the bearing contact is localized through modified gear-to-blade roll and bottom relief is applied.

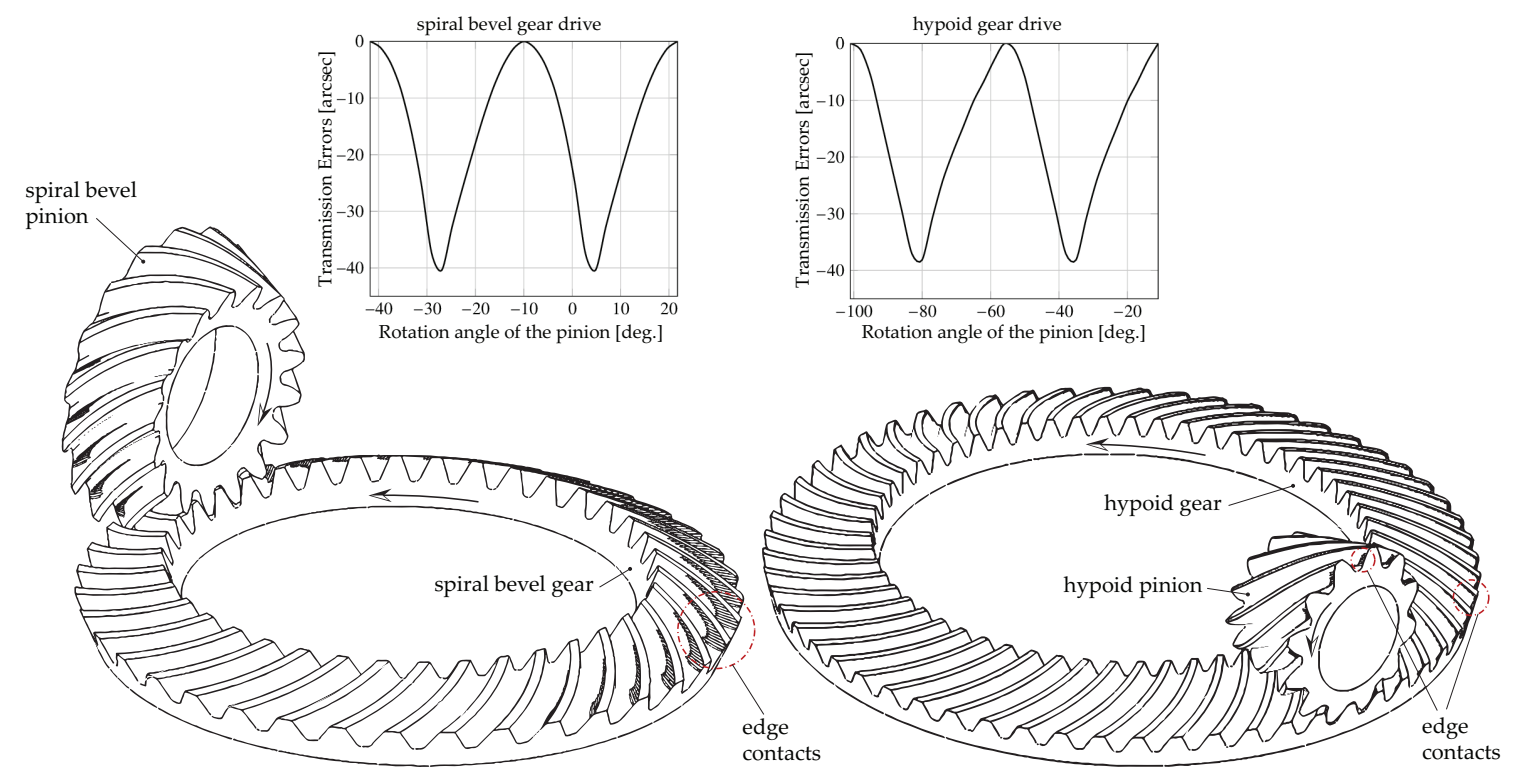

Figure 16: Illustration of contact patterns and transmission errors in the spiral bevel and the hypoid gear drives when alignment errors for counterclockwise rotation of the pinion (shown in Table 10) are present and not compensated. 
Table 8: Basic machine-tool settings and modified cutter data when crowning though a reference tilt angle is applied.

\begin{tabular}{lcc}
\hline Data & spiral pinion & hypoid pinion \\
\hline Radial distance [mm] & $S_{r 1}=73.998$ & $S_{r 1}=140.403$ \\
Cradle angle $\left[{ }^{\circ}\right.$ ] & $q_{1}=45.044$ & $q_{1}=45.404$ \\
Machine center to back [mm] & $\Delta X_{D 1}=0.0$ & Not Applicable \\
Machine center to crossing point [mm] & Not Applicable & $\Delta X_{C 1}=0.0$ \\
Sliding base [mm] & $\Delta X_{B 1}=22.205$ & $\Delta X_{B 1}=20.974$ \\
Blank offset [mm] & $\Delta X_{E 1}=0.0$ & $\Delta X_{E 1}=-15.0$ \\
Machine root angle $\left[{ }^{\circ}\right]$ & $\gamma_{m 1}=0.0$ & $\gamma_{m 1}=0.0$ \\
Tilt angle $\left[{ }^{\circ}\right]$ & $i_{1}=24.757$ & $i_{1}=14.912$ \\
Swivel angle $\left[{ }^{\circ}\right]$ & $j_{1}=-43.127$ & $j_{1}=-41.622$ \\
Gear-to-cradle roll ratio & $m_{1 c}=2.2353$ & $m_{1 c}=4.8333$ \\
Gear-to-blade roll ratio & $m_{1 b}=0.2941$ & $m_{1 b}=0.7500$ \\
Inner blade pressure angle $\left[{ }^{\circ}\right]$ & $\alpha_{b i}^{\prime}=18.993$ & $\alpha_{b i}^{\prime}=19.086$ \\
Outer blade pressure angle $\left[{ }^{\circ}\right]$ & $\alpha_{b o}^{\prime}=21.007$ & $\alpha_{b o}^{\prime}=20.914$ \\
\hline
\end{tabular}

Table 9: Parameters for application of modified gear-to-blade roll.

\begin{tabular}{lcc}
\hline Data & spiral pinion & hypoid pinion \\
\hline$\Delta \Psi_{g b}^{(c v)}[\operatorname{arcsec}]$ & 1000.0 & 100.0 \\
$\theta_{c o}^{(c v)}\left[{ }^{\circ}\right]$ & 15.0 & 15.5 \\
$\Delta \Psi_{g b}^{(c c)}[\operatorname{arcsec}]$ & 1000.0 & 100.0 \\
$\theta_{c o}^{(c c)^{\circ}}\left[{ }^{\circ}\right]$ & -20.0 & -4.0 \\
\hline
\end{tabular}

Application of machine-tool settings corrections as it was explained in Section 3 allows the bearing contact to be restored for one direction of rotation. Table 11 shows the new machine-tool settings that allow the bearing contact to be restored on the convex tooth side of the pinion teeth. Figure 17 shows the contact patterns and the transmission errors at both types of gear drives when the pinion rotates counterclockwise and the convex tooth sides of the pinion teeth are driving. Although these machine-tool settings work for one direction of rotation, they may not work for the other direction of rotation since the alignment errors are different (see Table 10).

Figure 18 shows the contact patterns and functions of transmission errors when the pinion tooth geometries that compensate errors of alignment for the counterclockwise rotation of the pinion are used for the other direction of rotation. In this case, the considered alignment errors are those due to clockwise rotation of the pinion (see Table 10). Edge contact and an increment of the level of transmission errors are observed in the spiral bevel gear drive when the pinion rotates clockwise. However, a shift of the contact pattern towards the heel without causing edge contact is observed in the hypoid gear drive when the pinion rotates clockwise. A light increment of the level of transmission errors is observed here as well. These contact conditions can be acceptable for the inverted direction of rotation in the hypoid gear drive, but not for the spiral bevel gear drive.

For the spiral bevel gear drive, application of a more severe profile crowning on the concave tooth side of the pinion teeth through a parabolic curve may allow to avoid edge contacts when the pinion rotates clockwise. A parabola coefficient of $0.003 \mathrm{~mm}^{-1}$ was considered for the outer blades of the pinion head-cutter. Figure 19 shows the contact patterns and functions of transmission errors in the spiral bevel gear drive for both directions of rotation. Here, pinion tooth geometries are compensated for the counterclockwise rotation of the pinion. It can be observed that the contact pattern is free of edge contact and the level of transmission errors is up to six arc seconds when the convex toot sides of the pinion teeth are driving. Here, the TCA algorithm considers as errors of alignment those illustrated in Table 10 for counterclockwise rotation of the pinion. Edge contact is avoided as well when the pinion rotates clockwise and the concave tooth sides of the pinion teeth are driving. Here, the TCA algorithm considers as errors of alignment those 

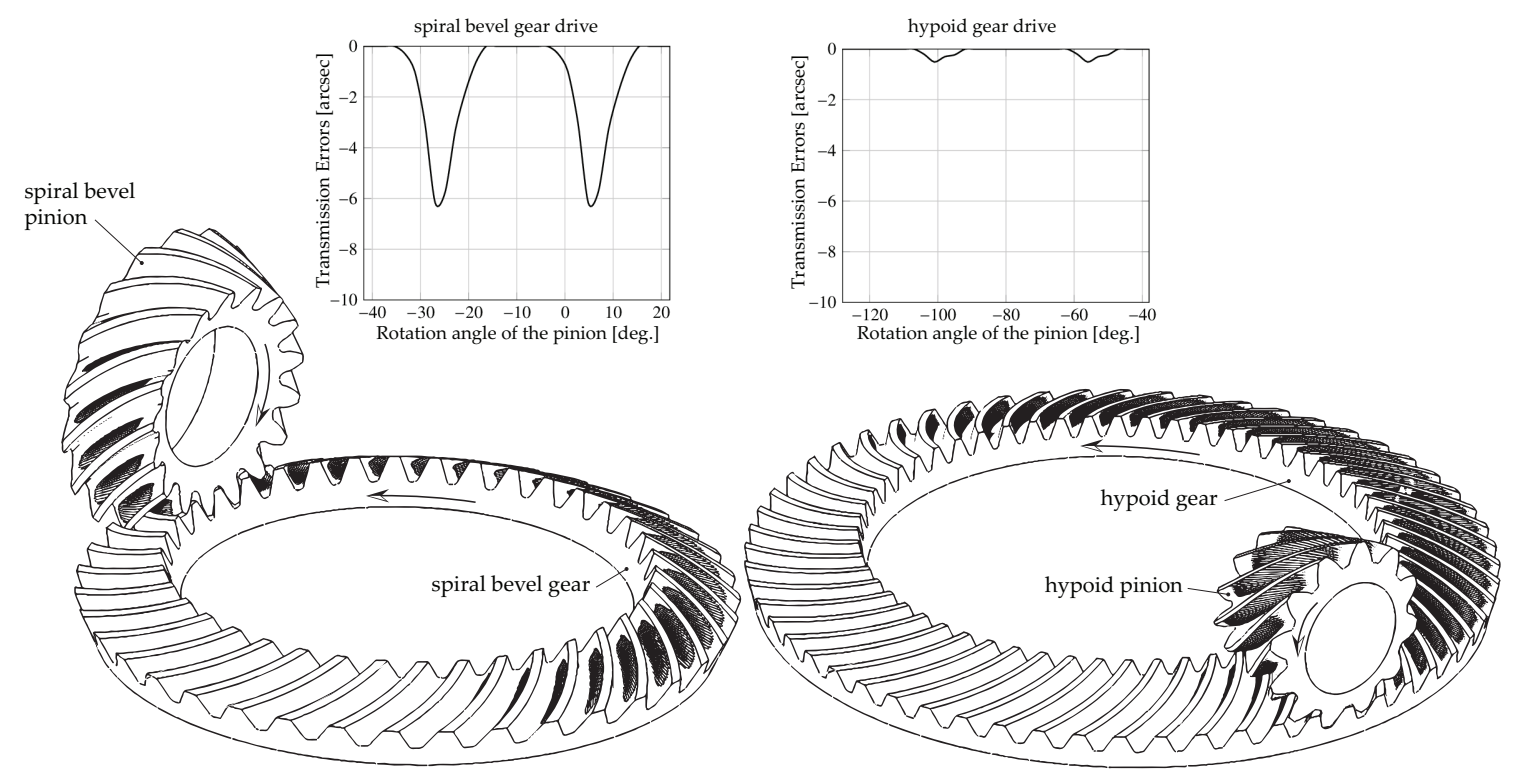

Figure 17: Illustration of contact patterns and transmission errors in the spiral bevel and the hypoid gear drives when alignment errors for counterclockwise rotation of the pinion (shown in Table 10) are present and compensated.
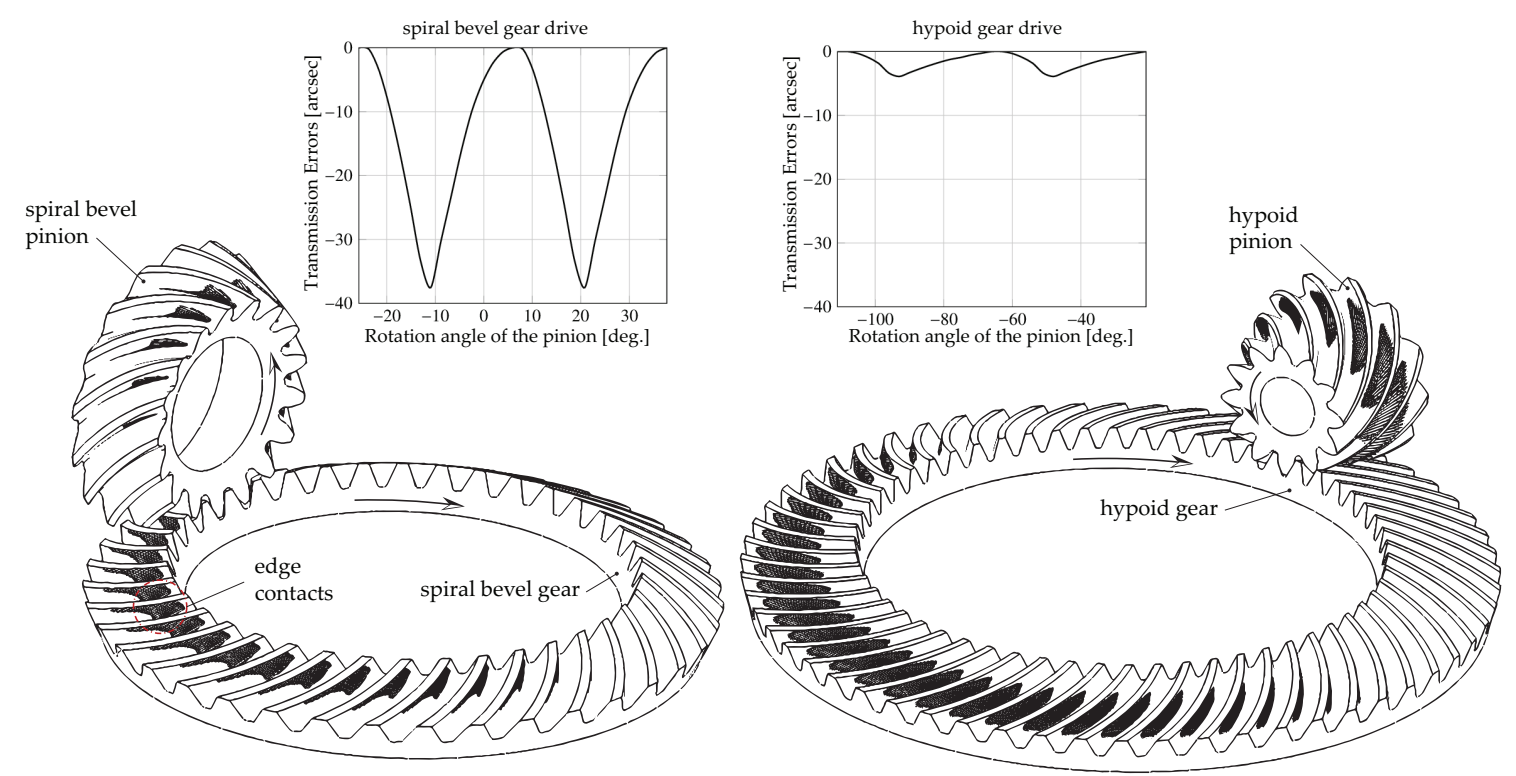

Figure 18: Illustration of contact patterns and transmission errors in the spiral bevel and the hypoid gear drives when compensated geometries for counterclockwise rotation of the pinion are rotated in opposite direction. 
Table 10: Alignment errors.

\begin{tabular}{lcccc}
\hline Data & \multicolumn{2}{c}{ spiral gear drive } & \multicolumn{2}{c}{ hypoid gear drive } \\
& pinion CCW & pinion CW & pinion CCW & pinion CW \\
\hline Shortest center distance error, $\Delta E[\mathrm{~mm}]$ & 0.313 & -0.368 & 0.457 & -0.479 \\
Pinion axial error, $\Delta A_{1}[\mathrm{~mm}]$ & -0.079 & 0.073 & -0.090 & 0.070 \\
Gear axial error, $\Delta A_{2}[\mathrm{~mm}]$ & 0.468 & -0.364 & 0.838 & -0.541 \\
Shaft angle error, $\Delta \gamma\left[^{\circ}\right]$ & -0.209 & 0.187 & -0.228 & 0.171 \\
\hline
\end{tabular}

Table 11: Basic machine-tool settings for the spiral bevel pinion and the hypoid pinion to compensate alignment errors for counterclockwise rotation of the pinion.

\begin{tabular}{lcc}
\hline Basic machine-tool settings & spiral pinion & hypoid pinion \\
\hline Radial distance [mm] & $S_{r 1}=73.732$ & $S_{r 1}=140.247$ \\
Cradle angle [ ${ }^{\circ}$ ] & $q_{1}=45.281$ & $q_{1}=45.515$ \\
Machine center to back [mm] & $\Delta X_{D 1}=-0.079$ & Not Applicable \\
Machine center to crossing point [mm] & Not Applicable & $\Delta X_{C 1}=-0.090$ \\
Sliding base [mm] & $\Delta X_{B 1}=23.678$ & $\Delta X_{B 1}=23.716$ \\
Blank offset [mm] & $\Delta X_{E 1}=-0.313$ & $\Delta X_{E 1}=-15.457$ \\
Machine root angle [ ${ }^{\circ}$ ] & $\gamma_{m 1}=-0.209$ & $\gamma_{m 1}=-0.228$ \\
Tilt angle $\left[{ }^{\circ}\right.$ ] & $i_{1}=24.102$ & $i_{1}=14.249$ \\
Swivel angle $\left[{ }^{\circ}\right.$ ] & $j_{1}=-44.719$ & $j_{1}=-44.484$ \\
Gear-to-cradle roll ratio & $m_{1 c}=2.2353$ & $m_{1 c}=4.8333$ \\
Gear-to-blade roll ratio & $m_{1 b}=0.2941$ & $m_{1 b}=0.7500$ \\
\hline
\end{tabular}

illustrated in Table 10 for clockwise rotation of the pinion. The severe profile crowning of the concave tooth sides avoids the edge contact. As a drawback, the level of transmission errors is increased up to 45 arc seconds. In this way, the compensation of errors of alignment as it was explained in Section 3 can be directed to the predominant direction of rotation to keep a formation of the bearing contact free of edge contact and a low level of transmission errors for a given design load. This compensation may require, as in the case of the spiral bevel gear drive, adjusting the crowning of the coast sides of the gear tooth surfaces to avoid edge contacts when the direction of rotation is inverted.

\section{Conclusions}

The performed research allows the following conclusions to be drawn:

- Analytical determination of basic machine-tool settings to get conjugated action in spiral bevel and hypoid gear drives where the gear is face-hobbed not-generated has been achieved. Tooth contact analyses show line contact and no unloaded transmission errors.

- Crowning of pinion tooth surfaces through application of a tilt angle shows a different surface topography at both tooth sides and the appearance of linear unloaded transmission errors, which make this type of crowning acceptable just for one direction of rotation.

- A method for crowning the pinion tooth surfaces through application of a modified roll periodic function has been proposed based on a two-term Fourier series. A periodic function is required since it is applied on a continuous non-indexing process. This crowning approach requires as well two processes for finishing both tooth sides. The results show that finishing of the convex tooth side does not undercut the finished concave tooth side, and viceversa. Geometry comparison shows as well that each crowning can provide its own surface 


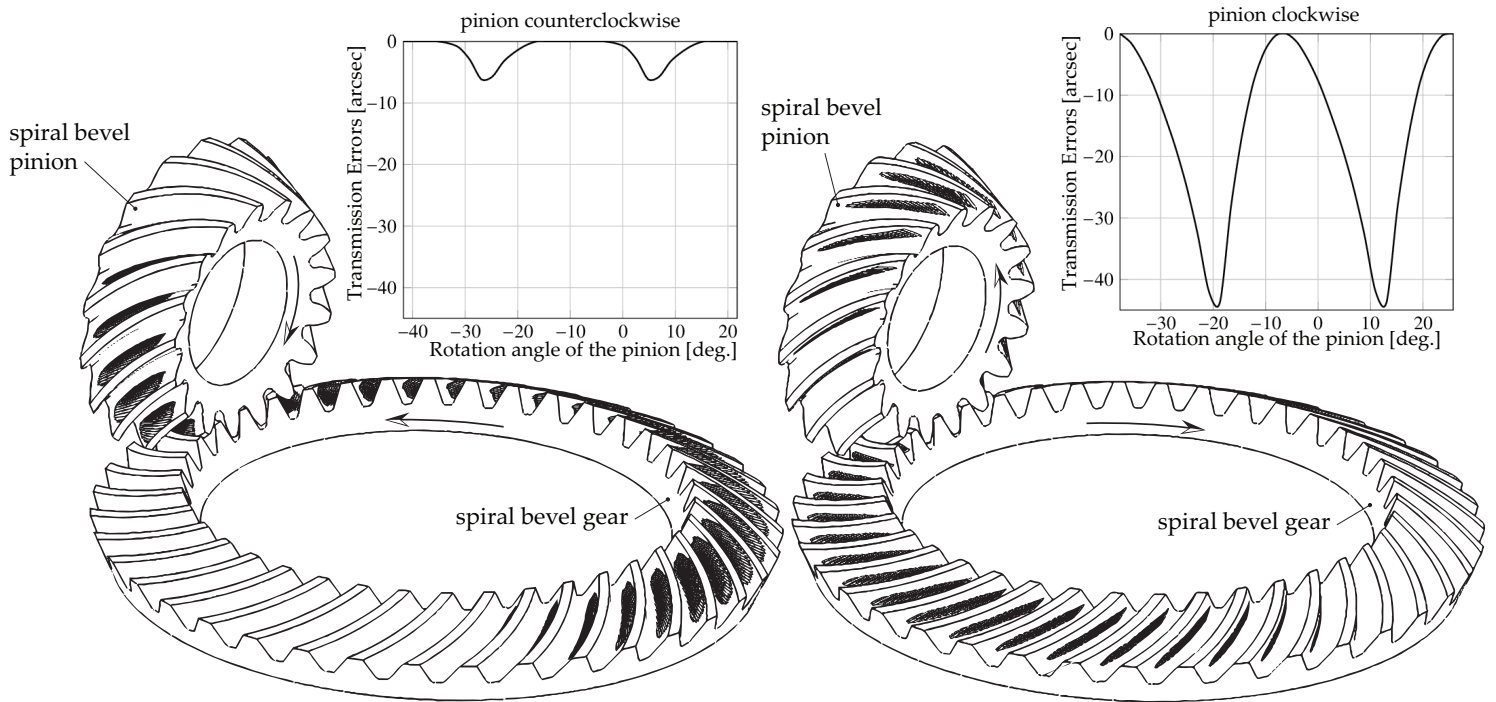

Figure 19: Illustration of contact patterns and transmission errors in the spiral bevel gear drive when compensated geometries for counterclockwise rotation of the pinion with a severe profile crowning on the coast sides are applied.

topography at each tooth side to get acceptable formations of the bearing contact for both directions of rotation. This approach does not provide unloaded transmission errors.

- Parabolic curves at the whole blade profile or at the bottom side of the blade profile have been applied for a better adjustment of the formation of the bearing contact and to avoid edge contacts, in spite of some unloaded transmission errors.

- Alignment errors for one direction of rotation can be successfully compensated for one direction of rotation. Adjusting of the surface topography at the coast tooth side of the pinion is required to keep an acceptable formation of the bearing contact when the direction of rotation is inverted. Such adjustment may be done either through the crowning provided by the proposed method of modified roll or by the application of parabolic profiles in the blades without modifying the surface topography of the other tooth side.

\section{Acknowledgements}

The authors express their deep gratitude to the Spanish Ministry of Economy, Industry and Competitiveness (MINECO), the Spanish State Research Agency (AEI) and the European Fund for Regional Development (FEDER) for the financial support of research project DPI2017-84677-P.

\section{References}

[1] H. J. Stadtfeld, Handbook of bevel and hypoid gears: calculation, manufacturing and optimization, Rochester Institute of Technology, Rochester, N.Y., 1993.

[2] Q. Fan, R. S. Dafoe, J. W. Swanger, Higher-order tooth flank form error correction for face-milled spiral bevel and hypoid gears, Journal of Mechanical Design, Transactions of the ASME 130 (7), 2008, 072601 (7 pages).

[3] Q. Fan, Tooth surface error correction for face-hobbed hypoid gears, Journal of Mechanical Design, Transactions of the ASME 132 (1), 2010, pp. 0110041-0110048.

[4] Y. P. Shih, A novel ease-off flank modification methodology for spiral bevel and hypoid gears, Mechanism and Machine Theory 45 (8), 2010 , pp. 1108-1124.

[5] A. Artoni, M. Gabiccini, M. Kolivand, Ease-off based compensation of tooth surface deviations for spiral bevel and hypoid gears: Only the pinion needs corrections, Mechanism and Machine Theory 61, 2013, pp. 84-101.

[6] I. Gonzalez-Perez, A. Fuentes, R. Ruiz-Orzaez, An approach for determination of basic machine-tool settings from blank data in face-hobbed and face-milled hypoid gears, Journal of Mechanical Design 137 (9), 2015, pp. 093303.

[7] F. L. Litvin, A. Fuentes, Gear geometry and applied theory, second edition, Cambridge University Press, New York, 2004. 
[8] A. Fuentes-Aznar, R. Ruiz-Orzaez, I. Gonzalez-Perez, Computational approach to design face-milled spiral bevel gear drives with favorable conditions of meshing and contact, Meccanica 53 (10), 2018, pp. 2669-2686.

[9] I. Gonzalez-Perez, A. Fuentes-Aznar, Analytical determination of basic machine-tool settings for generation of spiral bevel gears and compensation of errors of alignment in the cyclo-palloid system, International Journal of Mechanical Sciences 120, 2017, pp. 91-104.

[10] Q. Fan, Computerized modeling and simulation of spiral bevel and hypoid gears manufactured by Gleason face hobbing process, Journal of Mechanical Design 128 (6), 2006, pp. 1315-1327.

[11] Y.-P. Shih, Z.-H. Fong, G. C. Y. Lin, Mathematical model for a universal face hobbing hypoid gear generator, Journal of Mechanical Design, Transactions of the ASME 129 (1), 2007, pp. 38-47.

[12] Y.-P. Shih, Z.-H. Fong, Flank correction for spiral bevel and hypoid gears on a six-axis CNC hypoid generator, Journal of Mechanical Design 130 (6), 2008, pp. 062604.

[13] J. Du, Z. Fang, An active tooth surface design methodology for face-hobbed hypoid gears based on measuring coordinates, Mechanism and Machine Theory 99, 2016, pp. 140-154.

[14] J. Klingelnberg, Bevel gear: fundamentals and applications, Springer Berlin Heidelberg, Zurich, 2016.

[15] M. Vimercati, Mathematical model for tooth surfaces representation of face-hobbed hypoid gears and its application to contact analysis and stress calculation, Mechanism and Machine Theory 42 (6), 2007, pp. 668-690.

[16] A. Fuentes, J. L. Iserte, I. Gonzalez-Perez, F. T. Sanchez-Marin, Computerized design of advanced straight and skew bevel gears produced by precision forging, Computer Methods in Applied Mechanics and Engineering 200 (29-32), 2011, pp. $2363-2377$.

[17] ANSI/AGMA 2005-D03. Design manual for bevel gears, American Gear Manufacturers Association, 1500 King Street, Suite 201, Alexandria, Virginia 22314, 2005.

[18] G. A. Korn, T. M. Korn, Mathematics Handbook for Scientist and Engineers, second ed, McGraw-Hill, New York, 1968.

[19] A. Fuentes, R. Ruiz-Orzaez, I. Gonzalez-Perez, Compensation of errors of alignment caused by shaft deflections in spiral bevel gear drives, in: Mechanisms and Machine Science, Vol. 34, Springer International Publishing, 2016, pp. 301-319. 